\title{
AGROECOLOGÍA HISTÓRICA MAYA EN LAS TIERRAS BAJAS DE MÉXICO
}

\author{
HISTORICAL MAYAN AGROECOLOGY IN THE LOWLANDS OF MEXICO
}

\author{
Tlacaelel RIVERA-NÚÑEZ
}

Departamento de Agricultura, Sociedad y Ambiente, El Colegio de la Frontera Sur. Carretera Panamericana y Periférico Sur s/n Barrio María Auxiliadora, 29290, San Cristóbal de Las Casas, Chiapas, México. E-mail: tlacaelelrivera@gmail.com

\section{RESUMEN}

Submitted: 11/05/2020; Accepted: 20/06/2020

Que la Agroecología sea la alternativa agrícola del presente y del futuro mucho tiene que ver con el hecho de que ha sido una realidad histórica para un gran número de pueblos indígenas y campesinos alrededor del mundo. Propongo que dentro del creciente proceso de hibridación académica o recombinación interdisciplinaria que está experimentando la Agroecología resulta pertinente hablar de una "Agroecología Histórica". Dilucidar Agroecologías en clave diacrónica implica ampliar la escala geográfica de análisis hacia paisajes agrícolas históricos o palimpsestos, adentrarse a sus historias regionales, indagar la ingeniería ecológica de dichos paisajes, los procesos de imaginería social y simbolismo que han conducido a ellos, así como las estrategias de "r-existencia" que han permitido a los grupos indígenas y campesinos mantener vigentes sus agri-culturas en medio de una modernidad hostil pero envolvente. Los mayas de las Tierras Bajas en México representan una matriz cultural con una historia agrícola ininterrumpida -llena de discontinuidades más no colapsos- de cohabitar un mismo espacio geográfico a lo largo de cinco mil años. En este trabajo presento la Agroecología de la mente "Kanan K'aax" (cuidar el monte), el esquema de manejo agrosilvícola "jardín forestalmilpero", y la "terca y callada persistencia cultural" como ejes de la Agroecología Histórica entre los mayas yucatecos y lacandones de las Tierras Bajas. Concluyo reflexionando sobre el papel central que pueden tener las Etnociencias en un entendimiento de la Agroecología como conocimiento, práctica y movimiento orientados a redescubrir agriculturas históricas y traerlas a cuentas ante los retos y posibilidades de los horizontes políticos, sociales y ecológicos actuales y por venir.

Palabras-clave: Agroecología de la mente, manejo agrosilvícola, palimpsestos, presentes-pasadosfuturos, r-existencia

\begin{abstract}
That agroecology can be considered the agricultural alternative of the present and the future has much to do with the fact that it has been a historical reality for a large number of indigenous people and peasants around the world. I propose that within the growing process of academic hybridization or interdisciplinary recombination that Agroecology is experiencing, it is pertinent to speak of a "Historical Agroecology". Dilucidating agroecologies in a diachronic key implies expanding the geographical scale of analysis to historical agricultural landscapes or palimpsests, delve into their regional histories, investigating the ecological engineering of these landscapes, the processes of social imagery and symbolism that have led to them, as well as the strategies of "r-existence" that have allowed indigenous and peasant groups to maintain their agri-cultures in the midst of a hostile but enveloping modernity. The Maya of the Mexican Lowlands express a cultural matrix with an uninterrupted agricultural history -full of discontinuities but not collapses- of cohabiting in the same geographical space over five thousand years. In this paper I present the Agroecology of mind "Kanan $K^{\prime} a a x "$ (take care of the forest), the agroforestry management scheme "forest garden", and the "stubborn and silent cultural persistence" as axes of the Historical Agroecology among the Yucatecan and Lacandon Mayans of the Lowlands. I conclude by reflecting on the central role that the Ethnosciences can play in an understanding of Agroecology as knowledge, practice and movement oriented towards rediscovering historical agricultures and bringing them to account in the face of the challenges and possibilities of current and future political, social and ecological horizons.
\end{abstract}

Key-words: Agroecology of mind, agroforestry management, palimpsests, present-past-futures, rexistence 


\section{INTRODUCCIÓN}

El concepto "Agroecología" dentro del escrutinio científico se empleó de manera sumamente vaga en Europa entre 1940-1970 y comenzó a tomar particular relevancia en Latinoamérica y EE. UU. a partir de la década de 1980 (WEZEL et al., 2009; ALTIERI y NICHOLLS, 2017). El denominado "México profundo" amerita ser considerado uno de los epicentros del desarrollo académico de la Agroecología, ya que partiendo del estudio agronómico y ecológico de la agricultura tradicional de los mayas yucatecos y chontales de Tabasco, en 1976 Efraím Hernández- Xolocotzi acuña por vez primera el concepto de Agroecosistema y en 1981 Steve Gliessman define a la Agroecología formalmente como el estudio de las bases ecológicas de la agricultura (ROSADO-MAY, 2015; ASTIER et al., 2017; GLIESSMAN, 2017). Con el paso de los años estas concepciones basales se fueron entretejiendo con aportes como la visión de una agricultura alternativa de Miguel Altieri, la ecología agrícola de John Vandermeer, la sociología rural de Eduardo Sevilla-Guzmán, la política alimentaria de Peter Rosset, la experiencia de la agricultura orgánica cubana posterior al retiro de los apoyos de la Unión Soviética, las radicales críticas a la Revolución Verde por parte de organizaciones de base y ambientalistas en Brasil, así como el surgimiento e impacto del movimiento Campesino a Campesino en Centroamérica (FUNES et al., 2002; HOLT-GIMÉNEZ, 2006; BAPTISTA DA COSTA et al., 2017; GONZÁLEZ DE MOLINA y GUZMÁN, 2016). De manera tal, para finales de 1990 comenzó a plantearse la Agroecología ya no sólo como una ciencia surgente, sino también como una práctica y un movimiento social (WEZEL y SOLDAT, 2009; FERGUSON y MORALES, 2010).

En el tránsito de las primeras décadas del siglo XXI, la Agroecología se ha consolidado notablemente en cada uno de los campos que le constituyen. Como práctica resultan evidentes las procesos explícitos de incorporación de preceptos agroecológicos en las agriculturas de autoabasto de muchos grupos de pequeños campesinos, las lógicas de transición agroecológica en producciones comerciales de zonas rurales y urbanas y la consecuente apertura de toda una gama de mercados agrícolas alternativos, así como en las multifacéticas dinámicas territoriales de retorno al campo o recampesinización (VAN DER PLOEG, 2010; ALTIERI y TOLEDO, 2011; NIGH y GONZÁLEZCABAÑAS, 2015; WEZEL et al., 2016). En tanto movimiento social, en torno a la Agroecología se ha constituido por ejemplo La Vía Campesina: agrupación política, autónoma, plural y multicultural que integra a más de 200 millones de agricultores de 73 países de los cinco continentes en un fuerte llamado y una agenda de trabajo global que, a través de la participación en los foros alimentarios internacionales, busca la legitimación de la soberanía alimentaria como una forma de promover la justicia social, los derechos sobre el agua y las semillas, reformar redistributiva e integralmente el acceso agrario y, sobre todo, el desmantelamiento del poder monolítico de los agronegocios (DESMARAIS, 2007; ROSSET y MARTÍNEZ-TORRES, 2016). Finalmente, como ciencia, se han desarrollado equipos de trabajo, sociedades de investigación e incluso posgrados en un número creciente de universidades dirigidos propiamente a la formación en Agroecología, a través de los cuales esta ha transitado por diferentes escalas de estudio como la parcela, el ecosistema, los sistemas agroalimentarios y las políticas públicas; han sido incorporados enfoques metodológicos participativos y conocimientos no occidentales o "ciencia de lo concreto" (LÉVI-STRAUSS, 1964), y se han sumado elementos de análisis de una amplia gama de campos académicos (FRANCIS et al., 2003; WEZEL y SOLDAT, 2009; MÉNDEZ et al., 2013; SEVILLA-GUZMÁN y WOODGATE, 2014; VANDERMEER y PERFECTO, 2017; ALTIERI y NICHOLLS, 2017).

Como ha sucedido en otras áreas del conocimiento como la Ecología, la Geografía o la Antropología, la Agroecología en tanto campo en construcción parece estar superando las lagunas monolíticas que produce el estancamiento de no interactuar con otras disciplinas (DOGAN y PAHRE, 1990). Mucho tiene que ver con el propio hecho de que la Agroecología representa en sí misma lo que Toledo et al. (2009) denomina una "disciplina híbrida", esto es, un campo de conocimiento que se gesta a partir de fenómenos de interacción entre diferentes disciplinas en una suerte de "focos de infección”, en el caso que nos atañe inicialmente entre la Agronomía y la Ecología. Tomando como marco de referencia dicha idea, podríamos pensar entonces en la Agroecología como una disciplina híbrida de primera generación, entendida como resultado de múltiples, pero hasta cierto punto intuitivitos procesos dialógicos y, a las explícitas y más intencionadas recombinaciones disciplinarias que comienzan a tener lugar recientemente entre la Agroecología y otras áreas del conocimiento, como fenómenos de hibridación de segunda generación (RIVERA-NÚÑEZ et al., 2020; Figura 1).

En el presente trabajo busco contribuir precisamente a esta hibridación de segunda generación de la Agroecología, planteando que ello le permitirá mantenerse como un marco de investigación- 
acción de frontera: polisémica, ecléctica, adaptativa y postnormal. Particularmente la propuesta entraña la concepción de una "Agroecología Histórica", partiendo del reconocimiento de las hasta ahora incipientes dimensiones temporales y espaciales que los diferentes marcos teóricometodológicos de la Agroecología incorporan en su búsqueda por transitar hacia sistemas alimentarios sostenibles, a través de la aplicación de principios ecológicos y de justicia social en el diseño, manejo y defensa agrícola en un sentido amplio. Con el objeto de situar dicha lógica explícita e intencionada de recombinación disciplinaria -previamente híbrida- empleo la noción de "zona de contacto intelectual" (PRATT, 1991; MEYER y CRUMLEY, 2011) para esbozar de manera puntual pero no limitativa los aportes y novedades que considero pueden derivar los intercambios regularizados de la Agroecología con otros ámbitos del conocimiento y viceversa, principalmente con la Etnoecología, Antropología Ecológica, Ecología Histórica, Geografía Cultural y Arqueología Ambiental (Figura 1). Enuncio las bases de la propuesta hacia una Agroecología Histórica señalando la bonanza teóricometodológica de cada disciplina o campo de recombinación, para enfocar el presente trabajo en analizar detalladamente cómo los mayas de la Tierras Bajas de México ilustran a la perfección uno de esos casos a nivel mundial en el que una gran cultura agrícola, con cerca de 5,000 años de manejo tradicional, mantiene un grado notable de continuidad práctica y simbólica a pesar de una historia plagada de disrupciones, misma que merece ser considerada como un "presente-pasado-futuro" (SANTOS, 2000) agroecológico o lo que es lo mismo: una Agroecología Histórica.

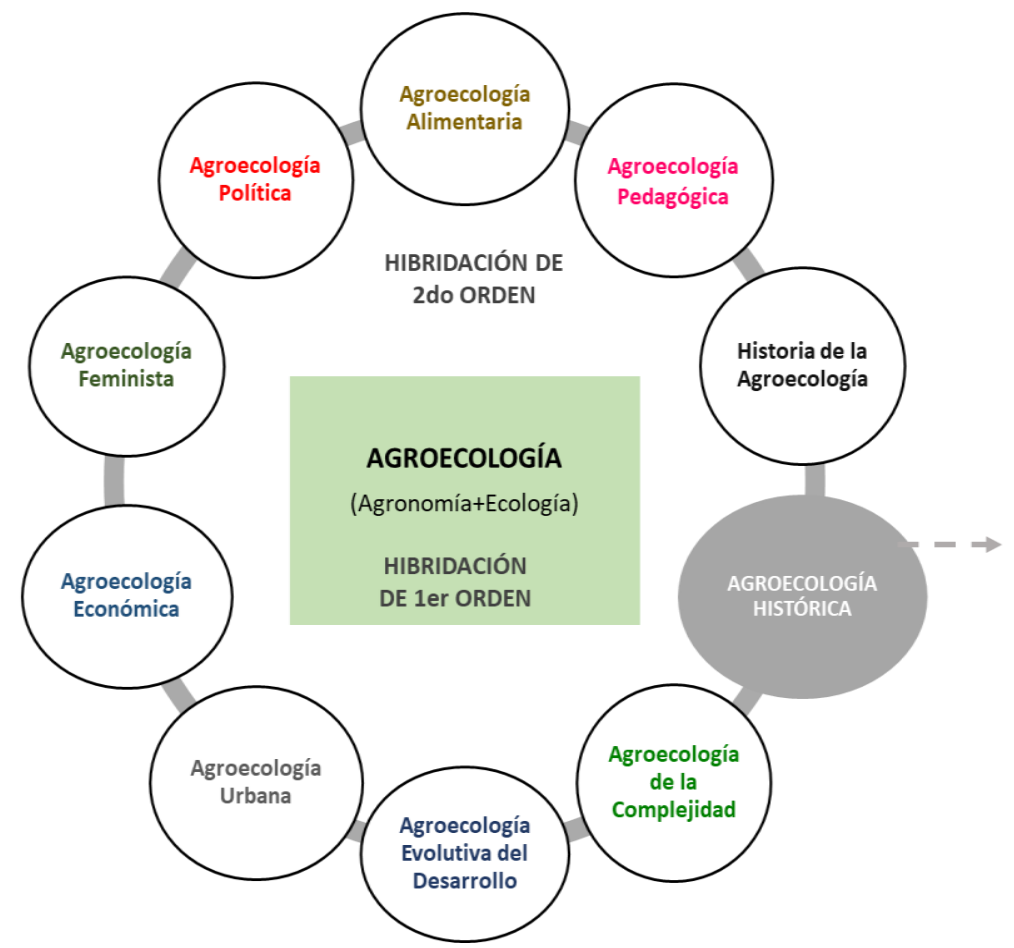

ZONA DE CONTACTO INTELECTUAL

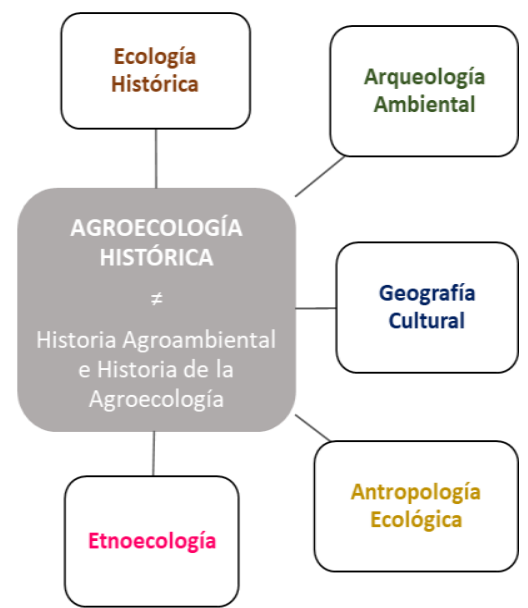

Figura 1. Proceso de hibridación de primer y segundo orden de la Agroecología y zona de contacto intelectual de la propuesta hacia una Agroecología Histórica.

\section{METODOLOGÍA}

El trabajo se fundamenta en una perspectiva metodológica que conjuga la investigación etnográfica y los estudios de caso (CRESWELL, 1998). El enfoque etnográfico se emplea en un sentido amplio, esto es, como el propio proceso de estudio de los significados e implicaciones materiales de algún aspecto o la totalidad de la vida cotidiana de los grupos culturales a través de la observación participante, así como plataforma para desarrollar una multiplicidad de instrumentos investigativos como los relatos de vida, entrevistas, análisis secundario de datos y cartografías participativas a partir de la inmersión prolongada en los sitios de estudio (ATKINSON y HAMMERSLEY, 1994; BERNARD, 2011). A su vez, los trabajos etnográficos son representados como estudios de caso múltiples e instrumentales, empleados de manera simultánea y subsidiaria para, a partir del conocimiento detallado de cada uno de ellos, profundizar en una temática común y generar postulados teóricos (YIN, 1994; STAKE, 1995). 
La región de estudio del presente trabajo son las denominadas "Tierras Bajas" mayas de México. En las investigaciones arqueológicas y antropológicas, la gran área maya que comprende el borde occidental de Honduras, la porción noroeste de El Salvador, Guatemala, Belice y en México la Península de Yucatán, Tabasco y la mitad oriental de Chiapas, suele subdividirse en dos mesoregiones: Tierras Altas y Tierras Bajas (TERÁN y RASMUSSEN, 2009). Las Tierras Bajas ocupan toda la Península de Yucatán y se extienden hasta los valles aluviales de Motagua, Copán y hacia las planicies aluviales de Tabasco, norte de Chiapas y oeste del Río Usumacinta (Figura 2). Como su nombre lo indica, se caracterizan por elevaciones menores a los 1,000 m.s.n.m y por compartir un clima cálido-húmedo y una vegetación tropical. Las Tierras Bajas presentan un doble rasgo de heterogeneidad a la par que cierta homogeneidad ecológica y cultural, producto de un gran ambiente tropical con muchos micro-topos, así como de una misma matriz cultural que ha derivado una diversidad lingüística y organizativa político-religiosa (TURNER, 1980). En la presente investigación reportamos tres estudios de caso en la porción mexicana de las Tierras Bajas mayas.

El primer caso lo representa el área conocida como Otoch Ma'ax Yetel Kooh (OMYK, Casa del Mono y el Jaguar en maya yucateco) y su estudio deviene del trabajo etnográfico de corte etnoecológico y de Ecología Política Histórica que he desarrollado desde 2012 hasta la fecha. La Casa del Mono y el Jaguar es un reducto de 5,367 ha de una amplia variedad de mosaicos vegetativos (selvas altas y medianas subperenifolias, selvas bajas inundables, pastizal inundable del tipo marisma y vegetación secundaria en diferentes estadios de sucesión) asociados a un complejo sistema de lagunas, cenotes y amplias depresiones inundables, con una notable congregación de fauna silvestre que le llevó a ser decretada en 2002 como Área Natural Protegida bajo la categoría de Protección de Flora y Fauna (GARCÍA-FRAPOLLI et al., 2007). Como se aprecia en la Figura 2, OMYK se emplaza en los límites fronterizos de los estados de Quintana Roo y Yucatán a 18 km de la Zona Arqueológica de Coba; la ocupación contemporánea del área, a partir de la década de 1950, la desarrollan tres pequeñas comunidades que en su conjunto suman 350 habitantes con orígenes tanto de municipios mayas peninsulares profundos como Xocén y Chemax, así como de municipios mayas rebeldes o Cruzoob (Pueblo de la Cruz, en maya yucateco) descendientes de participantes en la Guerra de Castas, como Muyil (REDFIELD y VILLA ROJAS, 1967; TERÁN y RASMUSSEN, 2005). Actualmente las comunidades combinan una estrategia de uso múltiple de los recursos naturales que incluye la milpa, el huerto familiar, la apicultura, los animales de traspatio y la cacería tradicional, con el ecoturismo, la producción de artesanías y la asistencia científica a primatólogos (TOLEDO et al., 2008; RIVERA-NÚÑEZ, 2014).

El segundo estudio de caso lo representa el análisis secundario al trabajo etnográfico de Antropología Ecológica y Ecología Histórica que desde hace ya más de 40 años viene desarrollando Ronald Nigh en la comunidad maya lacandona de Lacanja' Chansayab (LCh). LCh se ubica al noreste del estado de Chiapas, dentro de los límites del municipio de Ocosingo (Figura 2) sobre las selvas altas perennifolias y medianas subperenifolias que circundan al Río Lacantu'n (NIGH, 2008). La comunidad está poblada por alrededor de 300 habitantes cuya referencia se remonta a una compleja ontogénesis relacionada con otros grupos mayenses y, dentro de los cuales, ellos se autodefinen como los Hach Winik (Verdaderos Hombres, en maya lacandón o etnoglotónimo Jach-T’aan) ya que presentan la particularidad de tener más de 200 años habitando ese territorio específico lo que les ha significado una forma de vida altamente interrelacionada con los elementos de la selva (MARIONSINGER, 2000; DE VOS, 2002). El aprovechamiento de los recursos naturales gira en torno a un complejo manejo de la milpa, los montes y sistemas lagunares para el autoabasto, mismos que comienzan a ser remplazados por el ecoturismo como actividad económica principal (NATIONS y NIGH, 1980; TRENCH, 2005; PASTOR ALFONSO et al., 2012).

Finalmente, el último caso es representado por el análisis secundario de los datos que realizo al trabajo etnográfico de corte etnobotánico y agroecológico que vienen desarrollando Diana Cahuich y Ramón Mariaca en el ejido de X-Mejía (EXM) desde 2011 hasta la fecha (CAHUICH-CAMPOS, 2012; MARIACA-MÉNDEZ, 2012). Como se muestra en la Figura 2, EXM es una localidad rural que integra al municipio de Hopelchén en Campeche, y forman parte de los ejidos de la zona de refugio maya del siglo XVI que los españoles denominaron "La Montaña", hoy ubicados al norte de la Zona Arqueológica y la Reserva de la Biosfera de Calakmul (CAHUICH-CAMPOS et al., 2014). EXM presenta una dominancia vegetativa de selvas medianas subperennifolias y subcaducifolias, con una presencia menor de selvas bajas inundables y subcaducifolias (PORTER-BOLLAND et al., 2008). Se encuentra poblada por 477 habitantes integrados en 77 familias nucleares extensas de origen maya 
peninsular, cuyas actividades productivas son la agricultura milpera, el huerto familiar, la apicultura, la ganadería, la cacería tradicional y la extracción y recolección de los montes (CAHUICH-CAMPOS, 2012).

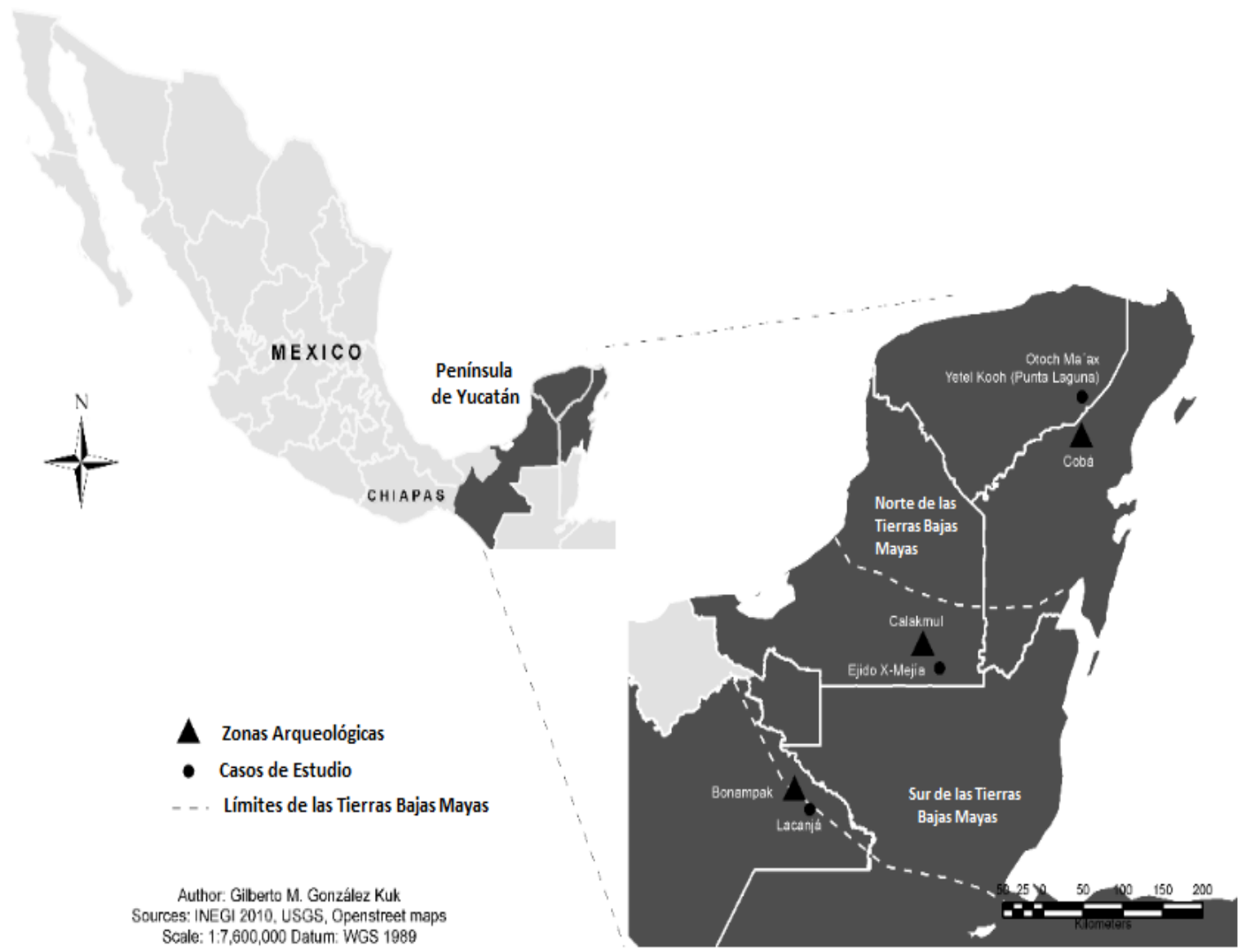

Figura 2. Ubicación de las Tierras Bajas mayas en México y emplazamiento de los casos de estudio (elaborado por Gilberto González Kuk con base en RIVERA-NÚÑEZ et al., 2020).

\section{RESULTADOS Y DISCUSIÓN}

Defino a la Agroecología Histórica como el estudio de las múltiples y acumulativas interacciones que, a través del tiempo y el espacio, las plurales sociedades humanas generan hacia los diversos ambientes ecológicos con los que co-inter-existen, a través de prácticas agrícolas, forestales, silvícolas, pecuarias, apícolas, acuícolas y pesqueras (en muchos casos conjugándolas) en aras de construir y administrar paisajes históricos capaces de satisfacer y compartir de manera sostenida, localizada, distributiva y no degradadora sus necesidades alimentarias, habitacionales, de salud e identitarias (en sentido amplio), sobre la base de los cada vez más cambiantes y confrontadores contextos sociopolíticos, culturales, económicos, técnicos y religiosos (RIVERA-NÚÑEZ et al., 2020). A partir de la experiencia de investigación en las Tierras Bajas, desarrollo los siguientes cinco rasgos teórico-metodológicos que me permitirán ilustrar la propuesta de una Agroecología Histórica maya: i) Historias regionales agroecológicas, ii) Los paisajes agroecológicos históricos como palimpsestos, iii) La agrodiversidad sobre la mesa como expresión de la construcción de nichos humanos, iv) Las agroecologías de la mente, y v) El silencio infrapolítico como otra forma de rexistencia agroecológica.

\section{Historias regionales agroecológicas}

Resulta imprescindible para el estudio de la Agroecología o para la conducción de algún tipo de accionar agroecológico reconocer que todo territorio en función deviene procesos de décadas, siglos o incluso milenios de complejas interrelaciones sociedad-naturaleza que se manifiestan en la configuración de paisajes y que pueden ser incorporados a los objetivos de la Agroecología mediante 
la comprensión de sus historias regionales. Para ello, la denominada Escuela Historiográfica de los Annales, a través de sus tres generaciones académicas y encabezada por los trabajos de Febvre (1953), Braudel (1980) y Le Goff (1991) son particularmente relevantes ya que facilitan la organización temporal y el análisis histórico del espacio, en donde el tiempo de años o décadas se nombra Événement (evento) y representan fenómenos episódicos de lapso corto; los rangos temporales de mayor cantidad de décadas hasta uno o dos siglos se denominan Conjoncture (ciclos) y representan procesos económicos, crisis y revoluciones en la historia regional; y las estructuras políticas y productivas que mantienen gran estabilidad a lo largo de siglos o milenios en la historia de una región se conocen como Longue Durée (estructuras).

Otras aproximaciones, además de la escuela francesa, pueden orientar lecturas sobre la historia regional de los paisajes para la Agroecología, como son: los enfoques etnohistóricos, las nociones sistémicas de Hysteresis (la historia importa) y los cambios cualitativos de regímenes o Tipping Points (HOLLING, 1973; ABEL, 1998; AGAR, 2004), la historia ambiental material (CROSBY, 2004; MCNEIL, 2003), así como las miradas geográficas en Ecología Humana (SAUER, 1956; CRUMLEY y MARQUARDT, 1990; ZIMMERER, 2000). Como técnicas fundamentales de bonanza de datos e información podemos identificar la revisión de los vastos archivos y documentos históricos que suelen existir en las regiones de trabajo de la Agroecología, así como las historias y relatos de vida apelando a la tradición oral que, aunque ciertamente erosionada, continúa prevalente y en manos de sujetos comunitarios claves que cada vez encuentran menos espacio de transmisión y legitimación de su conocimiento tanto hacia las nuevas generaciones, como en el diálogo de saberes con los interlocutores académicos (LEWIS, 1959; BERTAUX, 1989; DE VOS, 2004).

Ejemplifico, a través del caso de OMYK, cómo las aproximaciones agroecológicas que no se percaten del devenir regional de los paisajes en donde se desarrollan pueden recaer en la crítica que Wolf (1982) denominó como "los pueblos sin historia", extrapolada al hecho de procederes académicos bien intencionados pero que desconocen o no ponen al descubierto e incorporan los acervos de conocimientos y prácticas locales históricas, sino por el contrario promueven visiones generalistas y hasta cierto punto suplantadoras de una Agroecología no contextual (RIVERA-NÚÑEZ et al., 2020). En OMYK, por ejemplo, resultaría sumamente limitativo forjar un trabajo agroecológico que no contemple los cerca de cinco milenios de contingencia histórica de la región que, como muestra la Figura 3, ha transitado por un devenir paisajístico de seis grandes dinámicas culturales con diferentes lógicas de manejo de los recursos naturales que vendrían a aportar elementos importantes para construir una Agroecología Histórica particular o del lugar.

La Agroecología en clave diacrónica podría contribuir a recuperar prácticas históricas como la sedimentación y el redepósito de suelos o "bajos" provenientes de los sistemas lagunares y pantanos hacia las milpas, los Pet Kot (policultivos forestales, en maya yucateco; GÓMEZ-POMPA et al., 1987) y los huertos familiares contemporáneos; a manera de abonos naturales y enriquecimientos edáficos que incrementen la productividad agrícola-forestal y que pueden resultar actualmente viables para contrarrestar el creciente uso de insumos agroquímicos (GLIESSMAN, 1991; FEDICK et al., 2000; DUNNING et al., 2002). De igual manera, resultan necesarias aproximaciones agroecológicas abocadas a documentar la agrobiodiversidad asociada a las milpas y los huertos familiares y sagrados (del pueblo antiguo), para emprender programas tendientes a la diversificación de estos sistemas productivos que hoy en día están viviendo drásticos procesos de simplificación en la zona. Se podrían recuperar también manejos agrícolas tradicionales que se han ido erosionando con el paso del tiempo, como el Kimbal K'aax (pasear el monte, en maya yucateco) para la selección altamente especializada de los ciclos de sucesión agroforestal (TERÁN y RASMUSSEN, 2009), o la presencia comunitaria de los $\mathrm{Yum} I \mathrm{k}^{\prime} \mathrm{Ob}$ (cuidadores del viento, en maya yucateco) especialistas en controlar el fuego de las milpas para utilizar los vientos a favor de esparcir el material flamable por la zona de interés para lograr una quema nivelada y de baja temperatura (NIGH y FORD, 2019). Finalmente, y quizás una de las acciones más apremiantes que podría aportar la historia agroecológica regional en el área, sería establecer un diálogo informado con las autoridades gubernamentales y las organizaciones civiles que gestionan y soportan esquemas de conservación estrictos, totalitarios o "de fortaleza" en los espacios naturales protegidos (WILSHUSEN et al., 2012; WEST y BROCKINGTON, 2006; BÜSCHER y FLETCHER, 2019), sobre la importancia de las prácticas de manejo históricas realizadas por las comunidades locales para la plasticidad paisajística (VANDERMEER y PERFECTO, 2007; MORALES et al., 2007; HARVEY et al., 2008; CHAZDON et al., 2009). Prácticas agroecológicas históricas como la cacería para autoconsumo, la colecta y el aprovechamiento maderable de montes 
para subsistencia, o el uso controlado y sofisticado del fuego con fines agrícolas son actividades actualmente restringidas e incluso penadas legalmente en la región, las cuales, por el contrario, deberían ser reconocidas como patrimonio biocultural y derechos consuetudinarios del pueblo maya en el uso social e histórico de su territorio (BOEGE, 2008; BELLO BALTAZAR y ESTRADA LUGO, 2011; MERCON et al., 2019).

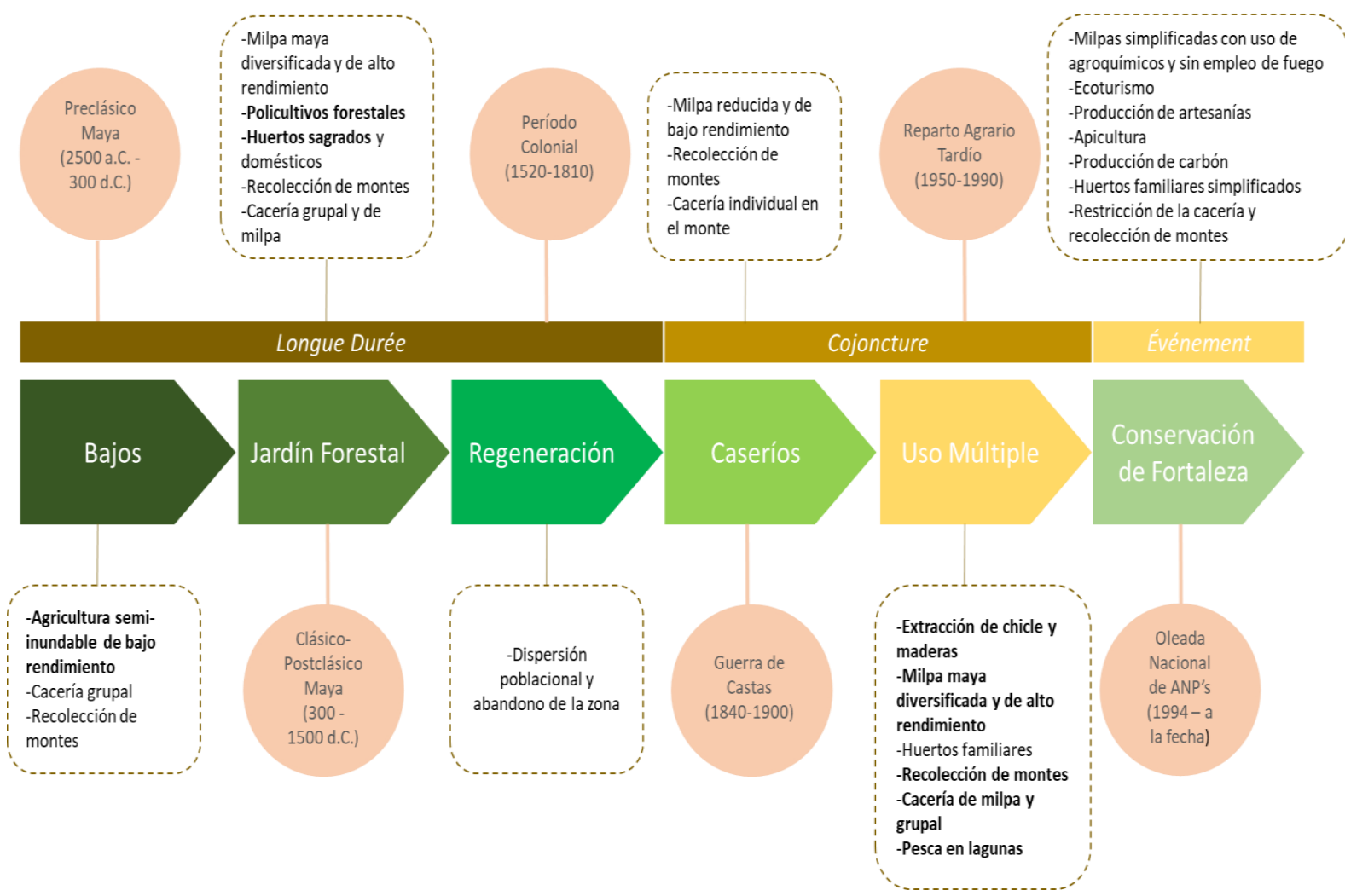

Figura 3. Historia regional agroecológica de Otoch Ma'ax Yetel Kooh en la Península de Yucatán, en la que se muestran seis grandes horizontes culturales con diferentes esquemas de manejo ambiental. Se resaltan en negritas las prácticas de manejo agroecológicas que se han erosionado o perdido históricamente.

\section{Los paisajes agroecológicos históricos como palimpsestos}

El planteamiento surge de la idea inicial el mito de lo prístino desarrollado por Denevan (1992) para sostener que la gran mayoría de los ambientes sobre la faz de la tierra han sido intervenidos -en diferentes grados a lo largo del tiempo- por las sociedades humanas y que no fueron sino las descripciones de los europeos que colonizaron los erróneamente denominados "nuevos mundos", quienes forjaron las ideas pasivas, efímeras y transparentes de los nativos o comunidades precolombinas hacia sus ambientes circundantes. Estas imágenes que en sus orígenes entrañaron estrategias de dominación al concebir a las poblaciones autóctonas como primitivas e incapaces de hacer florecer sus entornos, hoy son empleadas sin los debidos conocimientos históricos por la Biología de la Conservación y sus ramas afines (GÓMEZ-POMPA y KRAUS, 1992; CLEMENT y JUNQUEIRA, 2010). Consideramos que el talante histórico de la Agroecología debe trascender dichas nociones pictóricas y moverse más bien hacia el análisis diacrónico de los paisajes, esto es, el entendimiento de las perpetuas manifestaciones físicas o patrones del cambio ambiental intencionado generado por los grupos culturales a lo largo del tiempo para buscar sus aplicaciones o correcciones presentes y futuras (SAUER, 1925; CRUMLEY, 1987; BALÉE, 1998; ROBBINS y MOORE, 2013). Para ello, el empleo del antiguo concepto griego "Palimpsesto" (nuevamente grabado o escribir sobre lo escrito) adquiere particular importancia, ya que representa una significación operativa para dilucidar las capas sucesivas o superpuestas de disturbio que tienen lugar sobre los paisajes en tanto unidades de análisis (SANTOS, 1988; ALMADA, 2011; BAILEY, 2007; RIVERA-NÚÑEZ, 2019).

Es importante señalar que para dicho planteamiento histórico de la Agroecología el objeto de estudio fundamental lo representan los "disturbios humano-mediados", estos son, los cambios duraderos dirigidos por los grupos culturales sobre los paisajes para satisfacer sus necesidades, 
resultando algunas veces en detrimentos ambientales y en otros casos en la emergencia de propiedades favorables (BALÉE, 2006). Los procesos más comunes de disturbios humano-mediados alrededor del mundo y por ende los más estudiados, los representan: i) La gestión de suelos antropogénicos mediante procesos de reorganización y aporte, la alteración de patrones de drenaje y los interesantes hallazgos sobre la formación y regeneración de suelos microbiológicos como la "Terra Preta do Indio" en la cuenca amazónica (GLASER y WOODS, 2004; BARRERA-BASSOLS et al., 2006; ERICKSON y BALÉE, 2006; MARRIS, 2006); ii) La transformación y el manejo de los sistemas hidráulicos mediante la desviación, estrechamiento o expansión de vías fluviales para irrigación, la transformación con propósito agrícola de humedales, los vertederos de peces en ambientes riparios, la agricultura de balsas sobre los medios lacustres como las "Chinampas" (sesto de cañas en náhuatl) del Valle de México e incluso la coordinación ritual para el manejo agrícola multifuncional de cuencas hidrológicas como los "Subaks" en la Isla de Bali (GÓMEZ-POMPA et al., 1982; GLIESSMAN, 1991; ERICKSON, 2000; DUNNING et al., 2002; LANSING, 2012); iii) La arquitectura de bosques oligárquicos a partir del favorecimiento de árboles frutales, maderas preciosas y plantas de interés alimentario, curativo y económico posteriores al uso del fuego antropogénico y mediante la difusión cultural, que a la postre y considerando escalas espaciales amplias generan meta-paisajes que favorecen las diversidades $\alpha$ y $\beta$ de manera utilitaria, como en algunos casos de Australia, África Subsahariano, Este y Sur de Asia y, sobre todo, en Mesoamérica y la Amazonia (GÓMEZ-POMPA et al., 1987; PETERS et al., 1989; FORD, 2008; CLEMENT et al., 2015); y iv) El uso controlado del fuego para ganar espacio paisajístico hacia cultivos de interés y como mecanismo de fertilización del suelo (SAUER, 1925; LEOPOLD y BOYD, 1999; MISTRY et al., 2005; NIGH y DIEMONT, 2013).

La mayoría de las veces la magnitud y el grado de sofisticación de los disturbios humanomediados dependen de la contingencia histórica que tengan los grupos culturales en los ambientes ecológicos. Y aunque no es un hecho del todo lineal, generalmente es el tiempo -a través de la observación y la experimentación- el que permite a las sociedades llegar a conocer el funcionamiento de los espacios circundantes y las respuestas o adaptaciones que estos generan a los disturbios tanto antropogénicos como naturales. Con base en lo anterior, propongo que la contingencia histórica y los niveles de disturbios humano-mediados permiten clasificar (a) paisajes de primera naturaleza producto de eventos históricos y niveles bajos de disturbio, (b) paisajes culturales resultado de coyunturas históricas y niveles medios de disturbio, y (c) paisajes domesticados con altos niveles de disturbio producto de largas duraciones históricas (RIVERA-NÚÑEZ et al., 2020). En este sentido, un propósito central de la Agroecología Histórica es comprender la filogenia (origen y formación) de los paisajes históricos o palimpsestos para, a partir de la aplicación de principios de transición agroecológica, incidir en la ontogenia (desarrollo) de paisajes multifuncionales capaces de responder a las necesidades y los retos agroalimentarios y ambientales actuales. Las áreas del conocimiento que ofrecen un interesante campo de recombinación disciplinaria para esta dimensión de la Agroecología Histórica son principalmente la Geografía Cultural (DE LA BLANCHE, 1908; SAUER, 1925; CLAVAL, 1995), Ecología Histórica (CRUMLEY, 1994; BALÉE, 2006; AMSTRONG et al., 2017), Nueva Ecología (BOTKIN, 1990), Ecología del Paisaje (TROLL, 2003; RHEMTULLA y MLADENOFF, 2007), Arqueología Ambiental (EVANS y O'CONNOR, 1999) y Paleoecología (DODD y STANTON, 1990).

Uno de los principales ejemplos que se pueden usar para ilustrar dicho planteamiento dentro de las Tierras Bajas mayas lo representa, sin lugar a dudas, la elaboración del "jardín forestal-milpero" desarrollado por Ford y Nigh (2009). A partir del largo trabajo etnográfico y agroecológico de Nigh en LCh (NATIONS y NIGH, 1980; NIGH, 2008; NIGH y DIEMONT, 2013) y de los enfoques de Ecología Histórica y Paleoecología desarrollados por Ford $(2006 ; 2008 ; 2018)$ en la Reserva Arqueológica de Flora y Fauna El Pilar entre Belice y Guatemala, los autores plantean la novedosa conjetura de que las selvas mayas en su conjunto representan un meta-paisaje domesticado construido sobre la base del ciclo milpa-jardín forestal; estrategia culturalmente compartida de balance entre el manejo de las coberturas de la selva y las necesidades de cultivo que ha sido el producto de miles de años de experimentación y legado agrícola-forestal (GÓMEZ-POMPA et al., 2003; NIGH y FORD, 2019). Dentro de dicho planteamiento, la milpa maya representa un sofisticado e intensivo sistema agroforestal (en trabajo y rendimiento) que inicia con la generación de espacio para la siembra de los cultivos anuales de maíz-frijol-calabaza y la asociación de hasta otras 60 especies con más de 90 variedades (NATIONS y NIGH, 1980; TERÁN y RASMUSSEN, 2009), a través de la apertura de vegetación y pirolisis de baja temperatura que libera nutrientes al suelo como el calcio de las zonas 
tropicales, repone el nitrógeno, agrega fósforo, potasio, magnesio, manganeso y genera notables acumulaciones de bio-carbón a partir de la vegetación leñosa quemada, además de reducir la propagación de malas hierbas (FAUST, 2010; NIGH y DIEMONT, 2013). De manera generalizada en la Gran Región maya, durante los primeros cuatro o cinco años concernientes al inicio o "colonización" de manejo sucesivo, los agricultores se enfocan en conjugar la cosecha y re-siembra de los cultivos anuales con el manejo y favorecimiento de arbustos y árboles perenes que aseguren la regeneración forestal (FORD y NIGH, 2015). Posterior a esta primera etapa de sucesión, dependiendo de cada micro-región, se van desarrollando entre otras dos y cuatro fases diferenciadas de estratos de vegetación sucesiva que se van cerrando a partir de la competencia generada por el favorecimiento previo, y que terminan por convertir la selva en un jardín forestal con la dominancia de especies de interés para los grupos locales y en el cual continúan desarrollándose las funciones ecosistémicas de manera integral (FORD, 2008; NIGH, 2008; FORD y NIGH, 2009). Se sostiene que en la espesura de las selvas oligárquicas mayas cerca del $90 \%$ de las especies vegetales son de importancia para los grupos locales, identificándose con fines alimentarios (más de $60 \mathrm{spp}$.), medicinales (>50 spp.), para construcción (>30 spp.), melíferas (>20 spp.), para la alimentación animal (>20 spp.), ceremoniales (>20 spp.), así como otras 20 spp. entre ornamentales, textiles, repelentes y de uso como utensilios (TERÁN y RASMUSSEN, 2009; NIGH y FORD, 2019).

Respecto a lo anterior, LCh representa un caso concreto en donde la participación agroecológica podría jugar un papel muy importante en evitar la erosión del conocimiento agroforestal histórico, en re-articular el sistema agroalimentario y la culinaria propia, así como en garantizar la preservación ambiental mediante el manejo y la restauración a partir de las prácticas locales; aristas que hoy se encuentran fuertemente amenazadas por el desarraigo que ocasionan las misiones cristianas, el fallecimiento de importantes liderazgos cívico-religiosos y la brecha generacional, la suplantación de áreas naturales protegidas en la zona, así como por las agendas de desarrollo ecoturístico implementadas desde afuera y que hoy comienzan a constituirse como su principal modo de vida (COOK, 2016). Para articular una agenda agroecológica sensible a las condiciones culturales, nuevamente resultaría fundamental partir de un talante histórico que se interese en conocer la manera en cómo los mayas lacandones, a través de los años, han ido interactuando con los ambientes ecológicos circundantes hasta convertirlos en paisajes domesticados en donde se conjugan el policultivo de la milpa con hasta 56 especies de plantas útiles y la cacería de más de 10 especies de animales, la implantación de huertos familiares con más de 50 especies fundamentalmente alimentarias y la cría de alrededor de 10 especies de animales de traspatio, la pesca, caza y recolección de peces, camarones, cangrejos, cocodrilos y caracoles en los sistemas riparios y lacustres, así como la recolección de más de 50 especies propiciadas y cultivadas en los estados de sucesión del jardín forestal con importancia alimentaria, medicinal, constructiva, ceremonial, restauradora, para la producción de tejidos, como utensilios domésticos, agrícolas, de caza y navegación (NATIONS y NIGH, 1980; COOK, 2016; CONTRERAS y MARIACA, 2016; NIGH y FORD, 2019).

\section{La agrodiversidad sobre la mesa como expresión de la construcción de nichos humanos}

Los trabajos pioneros de Waddington (1959) y de Levins y Lewontin (1985) marcaron un parteaguas en el entendimiento de los procesos evolutivos tanto a nivel genético como a nivel organismico y ecosistémico al plantear que dichas unidades biológicas no son objetos pasivos a las fuerzas externas, sino por el contrario son co-creadores y moduladores de éstas. Ambos planteamientos presentan tres puntos de encuentro centrales: parten de una visión histórica, substituyen el concepto de adaptación por el de construcción, y emplean la escala de paisaje como dominio de análisis preferencial. A partir de estas notables contribuciones, en las últimas décadas ha surgido una agenda de investigación "eco-evo-devo" (BENÍTEZ, 2018) que está avanzando una nueva síntesis de la evolución de la vida en donde se trasciende la visión determinista, y se transita hacia un entendimiento constructivista y co-evolutivo, enmarcado en una corriente que bien podría denominarse Post-Darwinista (BLANTON y FARGHER, 2012).

Los estudios sociedad-naturaleza también han sido alcanzados por esta corriente de investigación, particularmente a través de la Teoría de la Construcción de Nichos Humanos. La teoría representa la síntesis y avance de las tesis sobre co-evolución gen-cultura, sistemas de desarrollo y aprendizaje socioconstructivista en un marco evolutivo. Concretamente la Teoría de la Construcción de Nichos Humanos plantea la inherente e inminente capacidad del Homo sapiens como especie biológica y de las sociedades humanas dadas como expresiones culturales, de modificar la relación 
funcional de otros organismos entre sí y respecto de su medio ambiente por medio de cambios activos y no aleatorios en una o varias interacciones ecológicas y patrones de espacialidad, con el objeto de favorecer la ocupación del nicho humano en los ahora ambientes selectivos modificados (ODILINGSMEE et al., 2003). Los académicos que se encuentran abonando la teoría desde enfoques socioambientales, aluden los siguientes rasgos fundamentales en los procesos de construcción de nichos humanos: a) representan procesos creativos de innovación consciente (LANSING y FOX, 2011), b) transforman los patrones de ordenamiento espacial en lo que podría denominarse arquitectura de paisajes (KENDAL et al., 2011), c) en consecuencia modifican el funcionamiento de los sistemas o desarrollan ingeniera de paisajes (LANSING y FOX, 2011), d) desembocan historias co-evolutivas (ELLIS, 2015), e) suelen surgir mecanismos de monitoreo reflexivo para conocer las resultantes de las transformaciones de estructuras y funcionamientos paisajísticos (KENDAL et al., 2011), f) existe toda una gama de repertorios culturales de transmisión de conocimientos y prácticas sobre los procesos pertinentes, y g) se busca asegurar la continuidad de estos procesos entre las futuras generaciones (ODLING-SMEE et al., 1996).

Una de las principales expresiones de construcción de nichos humanos lo representan las modificaciones en los arreglos de las diversidades $\alpha, \beta$ у $\gamma$ a escalas paisajísticas que generan los diferentes esquemas agrícolas (BOIVIN et al., 2016). Por ejemplo, se plantea la hipótesis de que los modelos de separación o land sparing que buscan liberar áreas para la transición forestal a la par que intensifican espacios de agricultura industrial, generan una curva de (agro)biodiversidad convexa muy distinta a la curva cóncava que se plantea para los modelos land sharing de integración agricultura y conservación de la biodiversidad a través paisajes agroecológicos (PERFECTO y VANDERMEER, 2010; TENZA-PERAL et al., 2011). En este trabajo, sugiero además como tercer escenario los metapaisajes agrícolas históricos o palimpsestos en los cuales, a través de los disturbios humanomediados descritos líneas arriba, circunscribo la hipótesis de la maximización o surgimiento de una cresta en la curva de (agro)biodiversidad en la que pueden coexistir especies en etapas sucesionales tempranas y tardías (Figura 4).

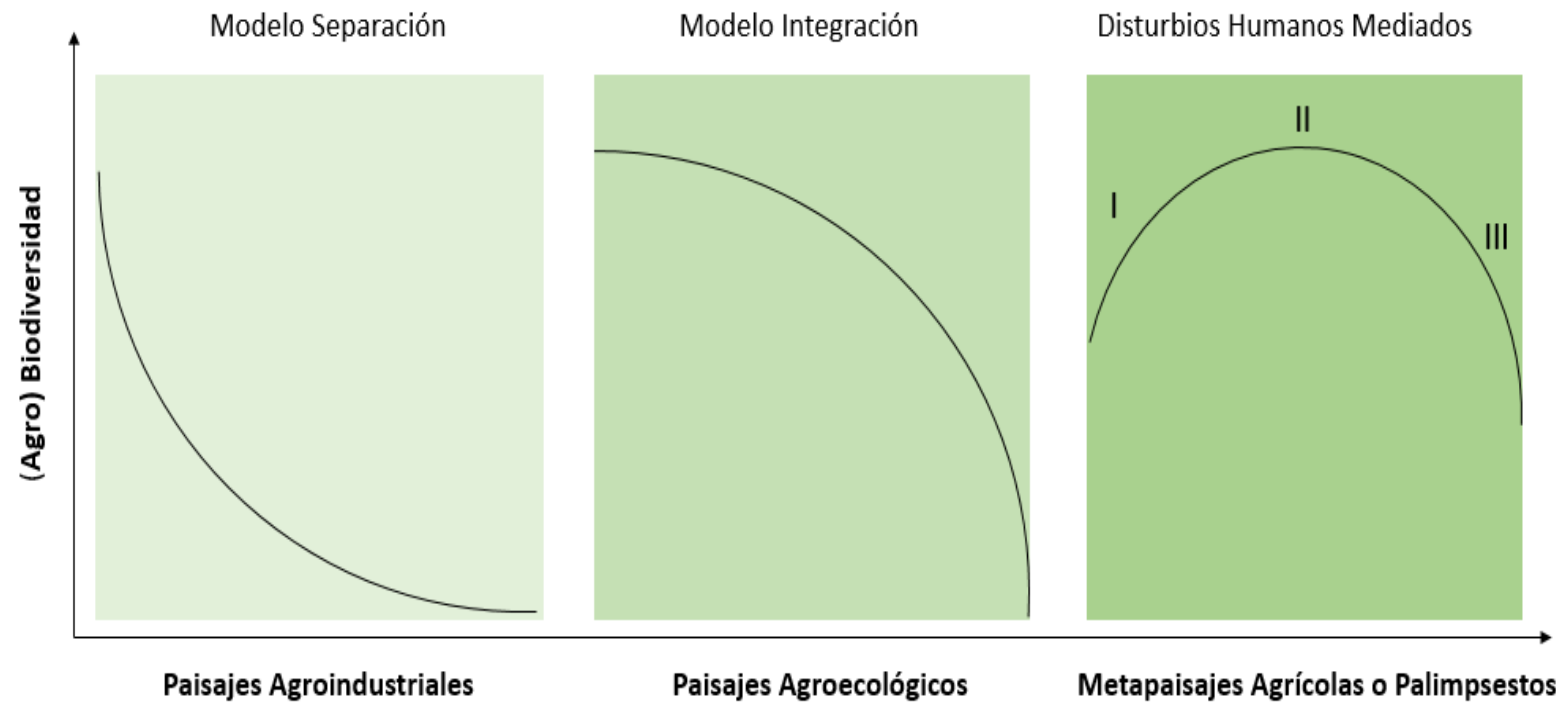

Figura 4. Hipótesis sobre las implicaciones para la (agro)biodiversidad de la construcción de nichos humanos a partir de paisajes agroindustriales, agroecológicos o palimpsestos. Dentro de los disturbios humanos mediados: I. A bajos niveles de perturbación ecológica la riqueza de especies disminuye a medida que aumenta la exclusión competitiva. II. En los niveles intermedios de perturbación la diversidad se incrementa porque las especies en etapas sucesionales tempranas y tardías pueden coexistir. III. A muy altos niveles disturbio la riqueza de especies se reducen debido a fragmentación de hábitat y altas tasas de migración (de referencia CONELL, 1978; PERFECTO et al., 2019; RIVERA-NÚÑ̃EZ et al., 2020).

Así, en la propuesta de una Agroecología Histórica maya, resultan de particular interés los procesos de intervención en los arreglos ecológicos de las diversidades biológicas por propósitos humanos alimentarios. Las áreas de traspatio que rodean la casa habitación de los mayas en la Península de Yucatán y que contienen plantas cultivadas, animales criados e infraestructura y trabajo 
familiar (MARIACA-MÉNDEZ, 2012), representan uno de los ejemplos más ilustrativos de lo anterior. En términos analíticos los huertos familiares mayas significan agroecosistemas complejos, adaptativos y multifuncionales de tipo forestal y agropecuario, en donde la familia que lo habita y ha conformado determina su estructura, forma y función a partir de procesos históricos de selección, domesticación, diversificación y conservación orientados principalmente al aprovisionamiento de alimentos (GONZÁLEZ-JÁCOME, 2007; MARIACA-MÉNDEZ et al., 2007). Tal como indican la fuente etnolingüística maya yucateca "Kuchil" (lugar en la casa maya donde se guarda cualquier cosa del monte que no es natural de ahí), los huertos familiares representan un proceso histórico creativo con un legado prehispánico y agudizado durante la política de congregación de los pueblos del siglo XVI en Yucatán- de arquitectura e ingeniería del paisaje en donde los jefes de hogar fueron seleccionando de los montes las especies de interés para trasladarlas a los espacios habitacionales manejados principalmente por las jefas de hogar, generando con ello paisajes domésticos con incrementos significativos en la diversidad $\alpha$, así como recambios paisajísticos o diversidad $\beta$ (MARIACA-MÉNDEZ, 2012; ver los trabajos afines en otras geografías de NABHAM, 2007; BALÉE, 2010; BARTHEL et al., 2013; GROESBECK et al., 2014).

En el ejido de X-Mejía, Municipio de Hopelchén Campeche, Cahuich-Campos (2012) documenta de qué manera el huerto familiar de los monteadores mayas es un área de construcción y conservación de agrodiversidad (sobre la mesa) que les brinda a las mujeres la capacidad de satisfacer gran parte del aprovisionamiento alimentario requerido; ejercicio sociocultural por el arraigo a la culinaria local y bioecológico en función de los procesos de domesticación y selección subyacentes (GREENBERG, 2003; JIMÉNEZ-OSORNIO et al., 1999). Los resultados de Cahuich-Campos (2012) muestran la vigencia actual del huerto familiar en Campeche, ya que representa una unidad de producción en donde se aprovechan con fines alimentarios 185 especies vegetales pertenecientes a más de 50 familias botánicas, así como más de diez especies de animales domesticados. Estas especies representan el $62 \%$ de los ingredientes requeridos para elaborar 50 platillos cotidianos o ceremoniales propios de la culinaria maya yucateca (Ibid: 2004); además, en el huerto familiar, tienen lugar notables expresiones culturales asociadas a la culinaria de dichas especies, como son los platillos preparados invariablemente con agua de lluvia colectada en piletas y la técnica de elaboración de alimentos en hornos subterráneos al rojo vivo, envueltos en hojas de plátano y cubiertos con hojas y ramas de árboles que permiten la cocción a partir del calor conservado o Pib (horno en maya yucateco; THOMPSON, 1975).

En síntesis, los huertos familiares entre los mayas peninsulares en lo particular y entre muchas otras culturas en lo general, representan pequeñas unidades paisajísticas que congregan la translocación de cientos de especies seleccionadas y procesos de domesticación; son uno de los mayores reservorios de la agrodiversidad mundial y, sobre todo, constituyen una de las unidades productivas que más contribuye a la cada vez más amenazada soberanía alimentaria rural y a los mercados locales y regionales por la venta directa al menudeo de parte de alguno de los miembros de la familia (JÍMENEZ-OSORNIO et al., 2015). La alimentación tradicional, no sólo es patrimonio biocultural, sino también base de la salud de los pueblos indígenas y campesinos, pues se ha demostrado que la mejor alimentación de un pueblo es la que ha producido su cultura a lo largo de siglos o milenios, debido a las adaptaciones genéticas del organismo a la misma (TERÁN y RASMUSSE, 2009). De manera tal, la participación agroecológica en el estudio y la acción de los huertos familiares y otras manifestaciones de construcción de nichos humanos en materia agroalimentaria, por su complejidad, convocan aproximaciones inter y transdisciplinarias en las que jugarían un papel central la Antropología de la Alimentación (MINTZ y DU BOIS, 2002), la Etnobotánica (BALICK y COX, 1996; ARMSTRONG y VETETO, 2015), la Ecología Agrícola (VANDERMEER, 1995; PERFECTO et al., 2019) y el Diseño del hábitat (NASSAUER y OPDAM, 2008).

\section{Las agroecologías de la mente}

Las múltiples e intensas interacciones de los grupos culturales directamente dependientes de la construcción de paisajes para subsistir, suelen derivar profundos sistemas cognitivos, simbólicos, lingüísticos y prácticos de representar y actuar el mundo fuertemente acoplados al funcionamiento de los entornos ecológicos (ATRAN, 1998; BERKES, 1999; INGOLD, 2002). Estos paisajes de conocimiento pueden ser representados a través de la noción de "Ecologías de la Mente" propuesto por Bateson (1973) para significar todas aquellas epistemologías o historias de la conformación de las 
ideas que otorgan sentido a los modos de ser y actuar culturales hacia los entornos ecológicos con lo que co-inter-existen. Concepciones similares han sido capturadas por notables académicos de las ciencias naturales y sociales. Por ejemplo, Vladímir Verdanski y Pierre Teilhard de Chardin (físicomatemático ruso y paleontólogo-filósofo jesuita francés, respectivamente) influidos por el concepto aristotélico de ethos desarrollaron la idea de "Noosfera" para aludir a la capa de pensamiento que tiene lugar en la biosfera y que se constituye a partir de procesos de diferenciación y evolución cultural (WYNDHAM, 2000). A su vez, tanto ethos como noosfera se perciben implícitos en las propuestas de "Ética de la Tierra" de Aldo Leopold (1949), "Ecología Mental" de Leonardo Boff (HATHAWAY y BOFF, 2009) y "Trama de la Vida" de Fritjof Capra (CAPRA y LUISI, 2014), las cuales refieren a la meta-comprensión teleológica de que las sociedades humanas pueden acoplar su accionar a la intrincada red ecológica.

Considero que hasta el momento los estudios agroecológicos se han limitado a comunicar dos aspectos relacionados con la investigación de dichas Ecologías de la Mente: i) establecer los rasgos constitutivos de la matriz práctica y ética que claramente diferencian la propuesta agroecológica del antagónico modelo agroindustrial (ALTIERI y NICHOLLS, 2008; GLIESSMAN, 2014), y ii) se han sumado a las iniciativas del llamado "Sur Global" que están construyendo una epistemología que busca la disolución de la idea del progreso y del desarrollo, cuyo epicentro la eclosión latinoamericana del "Buen Vivir" que adquiere rostros homólogos en diferentes geografías como Sumak Kawsay entre los Quechuas de Ecuador; Suma Qamaña entre los Aymaras de Chile; Nandareko entre los Guaranís de Paraguay, Argentina y Brasil; o Lekil Kuxlejal entre los Tzeltales de México (PAOLI, 2001; GUDYNAS y ACOSTA, 2011; GIRALDO, 2014). Estos campos de enunciación, sin embargo, suelen predisponer visiones esencialistas, dicotómicas y altamente normativas (véase crítica de AGARWAL, 2014; BERNSTEIN, 2014). Es importante transitar hacia miradas más singulares, a través de la recuperación de las "Agroecologías de la Mente" que se construyen en la intrínseca conexión entre los sistemas humanos de conocimiento y el funcionamiento de los paisajes agrícolas a través de la historia. Para ello, la Etnoecología (BROSIUS et al., 1984; TOLEDO, 1992; NAZAREA, 2016), la Filosofía y Epistemología Ambiental (BATESON, 1991; CALLICOTT, 1999; LEFF, 2007), la Antropología Ecológica (DESCOLA, 1996; MORAN, 2016), así como la Ecolingüística (STIBBE, 2015; FERNÁNDEZ-LLAMAZARES y CABEZA, 2017) representan zonas de contacto intelectual de suma bonanza teórico-metodológica para la investigación de las Agroecologías de la Mente de los pueblos originarios y de las sociedades campesinas.

Tomo como marco analítico la propuesta de etnopaisajes de Barrera y Toledo (2005) para presentar la Agroecología de la mente maya denominada Kanan K'aax (cuidar el monte, en maya yucateco). Acorde con los autores señalados, los etnopaisajes se constituyen a partir de la integración de los siguientes tres componentes: i) Paisaje imaginado, referente a los simbolismos otorgados al medio biofísico a través de la cosmovisión o "Kosmos"; ii) Paisaje cognoscitivo, describe el conocimiento intelectual sobre el funcionamiento del medio biofísico o "Corpus"; y iii) Paisaje técnico, alude al conjunto de prácticas de uso y manejo realizadas en el medio biofísico o "Praxis". En la Figura 5 muestro una representación esquemática del Kanan K'aax, construida con los milperosmonteadores más experimentados y de edad más avanzada de OMYK, en el cual se observa que los macehuales (los comunes, campesinos de a pie) se interrelacionan con el monte a través de tres prácticas principales: la milpa, la recolección de la selva y la cacería, todas ellas mediadas por la relacionalidad ontológica de que el monte posee sus propios dueños. Los macehuales, intermediados por un H'men (sacerdote maya yucateco) y su Zastun (piedra de poder) piden prestado, a través de múltiples prácticas ceremoniales agrícolas (Tabla 1), los recursos del monte a las deidades de Lu'um (espíritu de la tierra) para desarrollar las prácticas de manejo agrícolas, silvícolas, forestales y de caza que les permitirán la subsistencia de sus familias y comunidades. El complejo manejo de las etapas sucesivas de la selva es el principal componente del paisaje técnico. Los mayas macehuales practican el sistema monte-milpa-monte cuidado (o jardín forestal) iniciando con tres años de policultivo agrícola (Kool), después del cual dan paso a un estadio de sucesión selectiva del monte (Sak'aab) favoreciendo especies de interés utilitario y para la regeneración de la selva- el cual se emplea como comedero-trampa para la cacería tradicional e individual de ungulados (sobre todo la subespecie coevolucionada de venado cola blanca yuc, Odocoileus virginianus yucatanensis) pequeños mamíferos y aves (GREENBERG, 1992; SANTOS-FITA et al., 2013). Aproximadamente a los 15 años de sucesión, durante la etapa del Hubche', se decide si la composición de la vegetación es propia para 
continuar el ciclo hasta convertirse en montes altos y maduros mayores de 30 años (Kanal K'aax o Suhuy K'aax), o si es mejor que dé paso a policultivos forestales (Pet-Kot) o regresar a la milpa.

Como se puede apreciar, el Kanan K'aax representa una sofisticada imagen de la interrelación sociedad-naturaleza: una Agroecología de la mente integral con mediaciones simbólicas normativas, con un esquema pragmático de reproducción sobre el paisaje, con transmisión de conocimientos generacionales en tanto mecanismo de socialización, y con representaciones y asociaciones lógicas y discretas que adquieren sentidos lingüísticos. Se observado que el Kanan K'aax como Agroecología de la mente sobre la representación y actuación de los mayas en los paisajes agrícolas históricos se encuentra actualmente vigente en gran parte de los territorios de interior de la Península de Yucatán, en la región lacandona de Chiapas, en el Petén guatemalteco y en zonas mayas del Distrito de Cayo en Belice (NIGH y FORD, 2019; PUC-ALCOCER et al., 2019; RIVERA-NÚÑEZ et al., 2020; Figura 6). En estas cuatro regiones resulta evidente la calidad de la matriz paisajística de las selvas, y cómo las prácticas de manejo asociadas con el Kanan K'aax continúan representando una fuente importante de subministro agroalimentario, medicinal y para la construcción de viviendas vernáculas en las comunidades mayas. Es sumamente importante para el devenir agroecológico investigar este tipo de Agroecologías de la mente en los amplios contextos culturales alrededor del mundo en donde actualmente tiene lugar la Agroecología; pueden representar los ejes articuladores para, revitalizándolos con las nuevas prácticas y significaciones, transitar hacia agroecologías plurales que se vuelvan cada vez más difíciles de cooptar por las grandes agendas institucionales (véase GIRALDO y ROSSET, 2017), así como cada vez más funcionales por su arraigo a matrices culturales concretas.

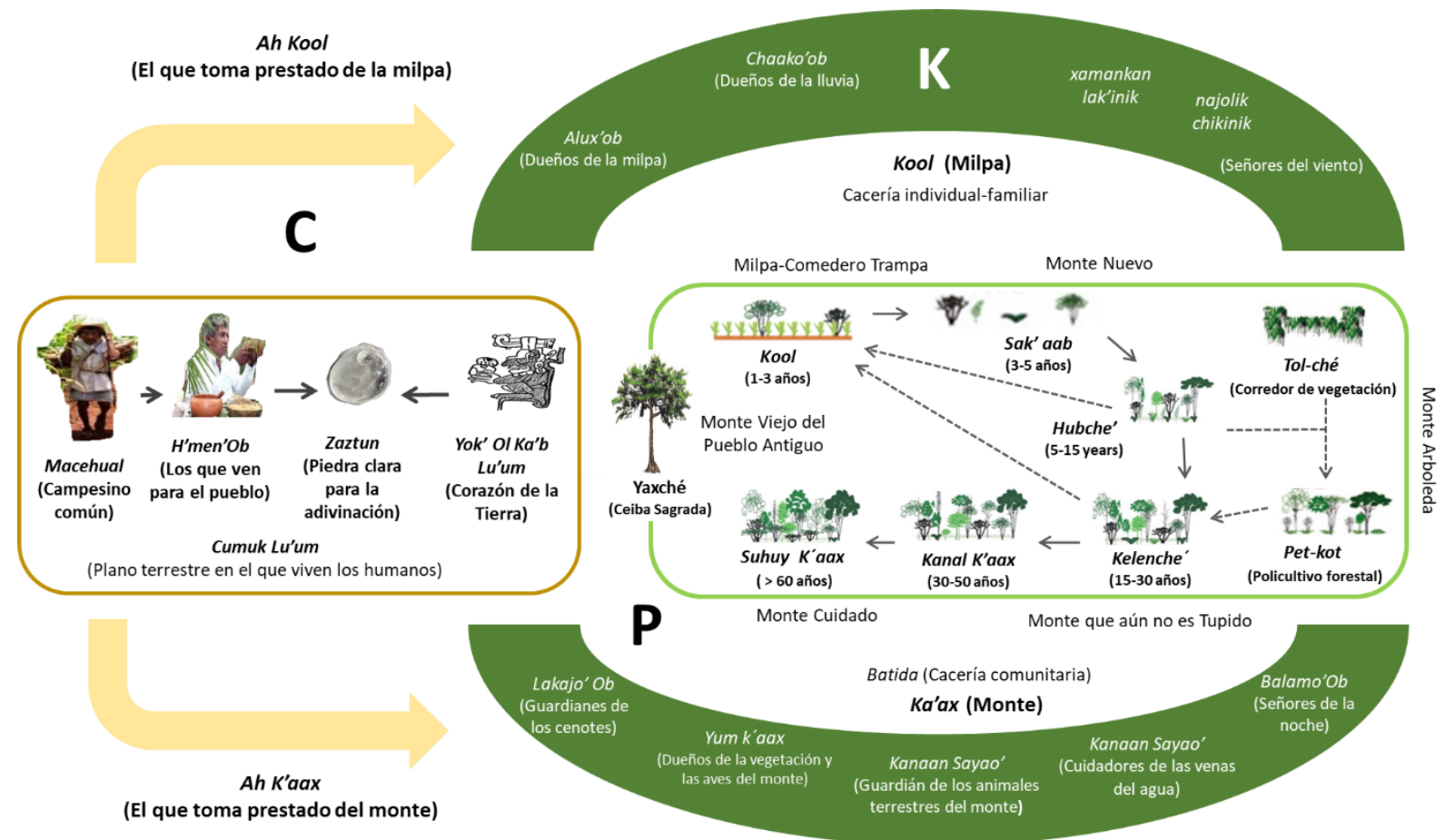

Figura 5. La Agroecología de la mente maya Kanan K’aax (cuidar el monte) expresado como un etnopaisaje histórico. $\mathbf{C}=$ Etnopaisaje cognoscitivo, $\mathbf{P}=$ Etnopaisaje práctico o de manejo, y $\mathbf{K}=$ Etnopaisaje ontológico relacional o simbólico (de referencia GARCÍA QUINTANILLA, 2000; RIVERA-NÚÑEZ et al., 2020). 
Tabla 1. Ceremonias agrícolas relacionadas con el Kanan K’aax en la Península de Yucatán, México (de referencia REDFIELD y VILLAROJAS, 1967; TERÁN y RASMUSSEN, 2005; RIVERA-NÚÑEZ et al., 2020).

\begin{tabular}{|c|c|c|}
\hline Ceremonia agrícola & Traducción & Sentido ritual \\
\hline U Lohol Ah Kin & $\begin{array}{l}\text { Rescate del Sacerdote } \\
\text { maya }\end{array}$ & $\begin{array}{l}\text { Para poder realizar las ceremonias agrícolas el H'men } \\
\text { debe de someterse cada dos años a un ritual de } \\
\text { redención seguido de un periodo de reclusión para } \\
\text { establecer contacto libre de impurezas con los todos } \\
\text { los señores, dueños y guardianes de las selvas mayas. }\end{array}$ \\
\hline Ch'a Chaak & Pedir por las Lluvias & $\begin{array}{l}\text { Consiste en avisar a los Chako' } \mathrm{Ob} \text { y a los Lakajo' } \mathrm{Ob} \\
\text { que ya se hizo la siembra y que ahora es necesaria su } \\
\text { intervención para que se logren las cosechas. }\end{array}$ \\
\hline Nuhu'Tal Unal & Primicias & $\begin{array}{l}\text { Forma parte del ritual agrícola de la milpa y tiene que } \\
\text { ver con agradecer la cosecha antes de tocar el maíz y } \\
\text { puede ser tan simple como ofrecer trece elotes } \\
\text { sancochados. }\end{array}$ \\
\hline U Janli Kol & Comida para la milpa & $\begin{array}{l}\text { Consiste en ofrecer elotes horneados en la tierra o } \\
\text { Pibinalo' } O b \text {, vino sagrado o Balch'e, pozol sagrado o } \\
\text { Saka' y el primer saco de elotes de la milpa a los Yum } \\
\text { K'aax' } O b \text { por permitirles el logro de la maduración } \\
\text { del maíz. }\end{array}$ \\
\hline Saka & Permiso & $\begin{array}{l}\text { Asociado a diferentes actividades del milpero- } \\
\text { monteador, como cuando va a cosechar o a mover un } \\
\text { apiario, antes de tumbar el monte o previo a la } \\
\text { siembra. }\end{array}$ \\
\hline$K^{\prime} e x$ & Cambio o transferencia & $\begin{array}{l}\text { Cuando el milpero-monteador carga un "mal viento" } \\
\text { por no haber avisado y pedido permiso para tomar } \\
\text { prestado, debe ofrendar un gallo virgen de patio y } \\
\text { enterrarlo en donde cargó el mal viento para que la } \\
\text { tierra se alimente del cuerpo y así le devuelva su salud. }\end{array}$ \\
\hline Hetz Lu'um & Fijar la Tierra & $\begin{array}{l}\text { Dar de comer a la tierra como símbolo de la } \\
\text { maternidad y para poder tomar prestado algo de ella. }\end{array}$ \\
\hline Looh K'aax & Revindicar el monte & $\begin{array}{l}\text { Cuando comienzan a suceder tragedias en el monte, } \\
\text { como campesinos perdidos, picaduras de culebras o } \\
\text { mala cacería, toda la comunidad tiene que convocar al } \\
\text { H'men para llevar a cabo esta ceremonia colectiva en } \\
\text { la que se contacta a la plana mayor de dioses y seres } \\
\text { sobrenaturales mayas, así como a los santos cristianos. }\end{array}$ \\
\hline
\end{tabular}

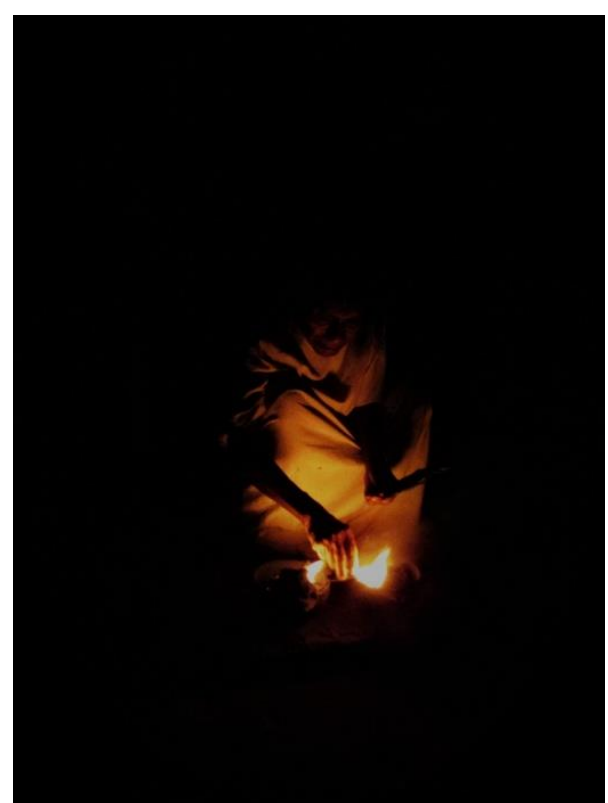

Figura 6. Y^j k'^yir (chamán) Hach Winik (lacandón, Hombre Verdadero) pidiendo a través de su sahumerio ritual al Kanankax (guardián del monte que habita en las cuevas de las montañas, cerca de la laguna en donde la selva es inviolable) que cuide a todo el monte, con sus montañas, sus árboles y sus nauyacas (cortesía de Elizabeth CASTRO-SALCIDO). 


\section{El silencio infrapolítico como otra forma de r-existencia agroecológica}

En las últimas décadas la investigación agroecológica ha avanzado notablemente en la instrumentación de las bases técnicas que la constituyen como una alternativa productiva no sólo viable, sino necesaria para afrontar los retos alimentarios, ambientales y económicos que caracterizan el curso del siglo XXI (ROSSET, 1999; DE SCHUTTER, 2011; GLIESSMAN, 2011). Ciertamente resueltos los fundamentos técnicos elementales, comienza a surgir un creciente interés académico por conocer los factores sociales clave que pueden llevar a que la Agroecología trastoque cada día más familias y territorios, así como políticas públicas y mercados, procesos que han sido denominados como "Scaling-out" y "Scaling-up", respectivamente (ALTIERI y NICHOLLS, 2008; PARMENTIER, 2014; ROSSET, 2015). En esta labor de masificar la Agroecología se ha iniciado un proceso de diferenciar geografías: los espacios de resistencia o "faros agroecológicos", por un lado, y los "espacios de dominación" por el otro (ROSSET y MARTÍNEZ-TORRES, 2015). Obviamente toda la atención se ha centrado en sistematizar los procesos exitosos que en materia agroecológica se encuentran impulsando los movimientos rurales organizados, el favorecimiento de políticas públicas en países progresistas de izquierda, la construcción de mercados alternativos, así como procesos educativos y metodologías sociales (ALTIERI y TOLEDO, 2011; MARTÍNEZ-TORRES y ROSSET, 2014; ROSSET y ALTIERI, 2017; MIER Y TERÁN et al., 2018; MCCUNE y SÁNCHEZ, 2018; VAL et al., 2019). A la beta de investigación que se interesa por el estudio de estos procesos se le comienza a denominar como Agroecología de los Movimientos Sociales (ROSSET y MARTÍNEZTORRES, 2012; BRESCIA, 2017), y las geografías en donde se desarrollan se vuelven muy distintivas por los procesos que abanderan: Cuba y la Asociación Nacional de Pequeños Productores (MACHÍN SOSA et al., 2013), el Movimiento de los Trabajadores Sin Tierra en Brasil (PELLEGRINI, 2009), el Movimiento Campesino a Campesino en Centroamérica (HOLTGIMÉNEZ, 2006; MCCUNE et al., 2016), la Agricultura de Presupuesto Zero en la India (ASHLESHA et al., 2017) o el Foro de Pequeños Agricultores Orgánicos de Zimbabue (SCOONES et al., 2010).

¿Qué pasa con la Agroecología fuera de sus geografías icónicas o de la esperanza? y ¿los movimientos sociales representan las únicas expresiones organizativas y políticas capaces de incorporar procesos agroecológicos o resinificar agriculturas? Interrogantes como estas figuran poco en la agenda de investigación aludida líneas arriba. Una vía para trasladar la mirada más allá de los movimientos sociales lo representa el acercamiento a la infrapolítica y la acción colectiva de los territorios agrícolas. En ello, adquieren particular relevancia la Sociología de la Insubordinación de James Scott (1990), así como la escuela micro-sociológica de interaccionismo simbólico norteamericano y de accionismo social europeo. El gran aporte que el trabajo de Scott puede representar para la Agroecología radica en distinguir la insubordinación negada declaradamente a obedecer (motivo de las revoluciones), de la desobediencia en la práctica o silenciosa (infrapolítica). Esta última designa a una plataforma de mecanismos y expresiones discretas e indirectas de resistencia a las que recurren los grupos oprimidos para soslayar las múltiples amenazas que les representan las estructuras de poder hegemónicas, entre las que destacan: los discursos ocultos, los cambios de comportamiento en función de la presencia de ciertos interlocutores, las contra ideologías identitarias, los excesos religiosos y rituales, los espacios exclusivos o nichos de autonomía, así como el uso compartido de ambigüedades para fomentar interpretaciones confusas entre sus interlocutores externos (SCOTT, 1990).

Por su parte, la integración de la escuela norteamericana y la europea de acción colectiva en tanto síntesis con mayor alcance, puede aportar elementos centrales para explicar cuáles son los procesos sociales y la historicidad de los grupos culturales que conducen o pueden detonar acciones colectivas para la defensa de territorios o la reivindicación de sistemas productivos, alimentarios y comerciales a través de la Agroecología en geografías infrapolíticas. El interaccionismo simbólico brinda notables luces para adentrase a los comportamientos cotidianos institucionalizados (COLLINS, 1996), así como a los significados y símbolos sobre la acción social (GOFFMAN, 1969), y para determinar de qué manera estos se pueden traducir en movilizaciones de individuos que conduzcan al restablecimiento de ordenes amenazados, al saneamiento de un sistema o incluso a cambios en los regímenes de control social (PARSONS, 1964). De manera complementaria, la escuela europea de accionismo colectivo aporta los andamiajes necesarios para escudriñar las capacidades de las sociedades para actuar sobre sí mismas (MELUCCI, 1994) a través de los sistemas de acción histórica, estos son, el conjunto de orientaciones sociales y culturales por los cuales la historicidad ejerce fuerzas 
sobre el funcionamiento de una sociedad dada y de sus relaciones de clase (ALBERONI, 1984). Al respecto, Touraine (1984) identifica los siguientes tres mecanismos para que la acción colectiva, a través de la historicidad, tenga lugar: i) la identidad como capacidad de los sujetos de reconocerse como parte de una sociedad dada, ii) surgir una oposición social respecto a las anomalías o la identificación de adversarios (despojos, el Estado, etc.), y iii) tener la energía y capacidad para construir un proyecto que rompa con las condiciones de historicidad o que busque reforzar o resignificar las existentes.

Trasladar estas perspectivas teóricas al caso de la agri-cultura de los mayas yucatecos resulta un ejercicio ilustrativo para generar algunas reflexiones iniciales sobre el papel que puede jugar la Agroecología Histórica como un marco científico, práctico y de acción social que busca resignificar las agriculturas tradicionales en aquellas geografías que hoy en día no figuran como icónicas para la investigación agroecológica. En dicho ejercicio, lo primero que habría que responder es ¿cómo han hecho los mayas yucatecos para persistir tan vigentes en términos identitarios y territoriales ante los múltiples flagelos lacerantes que amenazan su autodeterminación cultural, y bajo la presencia de muy pocos movimientos sociales o banderas explícitas de resistencia? La respuesta es clara para los que hemos tenido la oportunidad de caminar con el pueblo maya yucateco: infrapolítica (WARMAN, 1985). Considero que precisamente detrás de sus polifacéticos lenguajes ocultos -pues son expertos del manejo de discursos ambiguos, de blindar espacios de exclusividad para sus miembros culturales, de las prácticas ceremoniales y de un bajo perfil político-radica el hecho de que representen el pueblo originario de México más homogéneo, extendido y que preserva una de las mayores continuidades en su matriz cultural. Y justamente dentro de esa "terca y callada persistencia histórica" de los mayas yucatecos, el sistema milpero y el aprovechamiento integral de los montes continúan representando una opción agrícola para la región, por la cantidad de terreno que aun actualmente les es dedicado y el número de campesinos que les desarrollan (TERÁN y RASMUSSEN, 2009); sin dejar de reconocer la simplificación que el tiempo y el recambio generacional han representado para estas prácticas de manejo, así como el abandono de una proporción considerable de la población que ha optado por sumarme marginalmente a los modos de vida que promete la "modernidad".

Toda vez reconocido que la infrapolítica representa una de las principales estrategias de persistencia cultural para los mayas yucatecos, los pasos fundamentales para dimensionar los alcances de una propuesta de Agroecológica Histórica en esta región serían conocer: ¿qué amenazas y agrimensores perciben los mayas peninsulares sobre la continuidad de sus sistemas agrícolas y esquemas múltiples de manejo del monte?, ¿de qué manera sus prácticas ambientales silenciosas y lenguajes culturales ocultos pueden concatenar sistemas de acción histórica? y ¿qué puentes están dispuestos a tender con otros actores sociales (como la comunidad académica) en aras de emerger estrategias colectivas de restablecimiento del orden histórico, de saneamiento de las confrontaciones actuales o incluso para promover cambios favorables en el control de su régimen histórico? La Ecología Política (BRYANT y BAILEY, 1997; ESCOBAR, 1998; MARTÍNEZ-ALIER, 2002; ROBBINS, 2011; GONZÁLEZ DE MOLINA et al., 2019) y la Sociología Rural (LONG y ROBERTS, 2005; SEVILLA-GUZMÁN, 2006) representan marcos de investigación centrales para acompañar a la Agroecología en la tarea de abonar a la defensa y resignificación de una de las expresiones agrícolas más complejas y vigentes que ha experimentado la historia de la humanidad (FORD, 2018; RIVERA-NÚÑEZ et al., 2020).

\section{CONSIDERACIONES FINALES}

A pesar de que se reconoce que el conocimiento ecológico tradicional y las Etnociencias representan uno de los pilares constitutivos de la Agroecología (GLIESSMAN, 1990; ALTIERI, 1993; SEVILLA-GUZMÁN y MIELGO, 1994; TOLEDO, 2005), poco detenimiento se ha brindado a analizar las dimensiones temporales y escalas espaciales de los procesos agroecológicos en los territorios donde tienen lugar dichas sabidurías y prácticas locales. Sobre todo la dimensionalidad temporal, nos llevaría a establecer una suerte de clasificación de diferentes agroecologías en función de sus coyunturas históricas: i) Agroecologías Emergentes, manifiestas, por ejemplo, en las experiencias periurbanas que se encuentran desarrollando colectivos y comunidades migrantes y desplazadas en los EE. UU. (MARES y PEÑA, 2010) o el estilo organic farming en California (GUTHMAN, 2000); ii) Agroecologías Límite, surgidas en situaciones de conflicto como la agricultura cubana posterior a la caída del bloque socialista o "periodo especial en tiempos de paz" (MACHÍN-SOSA et al., 2013), la búsqueda de soberanía alimentaria en la Venezuela "saudita" 
(HERRERA et al., 2017), o la promoción agroecológica de LVC en un contexto de disputa entre la reforma agraria y el intento golpista en Zimbabwe (MOYO, 2011; ROSSET y MARTÍNEZ-TORRES, 2012); y finalmente iii) Agroecologías Históricas, generalmente correspondientes a las agriculturas surgidas en los Centros Vavilov de origen de plantas cultivadas (HARLAN, 1971) y a las regiones megadiversas, destacando, por ejemplo, las agroecologías mesoamericanas (PALERM y WOLF, 1972; GONZÁLEZ-JÁCOME, 2011), agroecologías andinas (TAPIA, 2002; ALTIERI y TOLEDO, 2011), agroecologías amazónicas (CLEMENT, 2006; CLEMENT et al., 2015), así como algunas agroecologías en el continente asiático (LANSING, 2012; VAN DER PLOEG et al., 2014).

Cada una de las agroecologías propuestas es resultado de diferentes contextos históricos y escalas espaciales. Por lo tanto, el estudio del devenir que ha dado lugar a cada expresión agroecológica genera contribuciones particulares: los talantes emergentes nos hablan del surgimiento de nuevas sociologías que se articulan a partir de prácticas y discursos agroecológicos; las situaciones límites expresan el carácter contestatario y utópico-real de la Agroecología como dispositivo de defensa y reconstitución territorial (VAL et al., 2019); y las manifestaciones diacrónicas nos traen a cuentas los profundos legados agrícolas y ecológicos de grupos culturales que han interactuado íntimamente con sus entornos durante largos períodos de tiempo (FAUST y FOLAN, 2016; NIGH y FORD, 2019; RIVERA-NÚÑEZ et al., 2020). Resulta sumamente importante para la investigación agroecológica brindar atención especial a las Agroecologías Históricas como la maya de las Tierras Bajas de México expuesta en este trabajo ya que, como he mostrado, (a) representan sistemas de producción de alimentos y prácticas culinarias capaces de contrarrestar localmente los imperios alimentarios, (b) expresan prácticas agrícolas tradicionales y reservorios in situ de germoplasma que pueden permitir una alta independencia de la agroindustria, (c) incorporan planes de administración multifuncionales e integrales del paisaje que pueden ofrecer alternativas a las políticas conservacionistas de fortaleza instauradas por gobiernos y promovidas por organizaciones civiles ambientalistas (ROBBINS y MOORE, 2013), y (d) desafían las narrativas dominantes del "Antropoceno" y la "Huella Ecológica" a través de proponer las nociones contestatarias de "Antropogénesis" y "Manos Agroecológicas" o Agroecological Handprint, ambas connotando la capacidad de dar forma, moldear o esculpir paisajes agrícolas como resultado de la experiencia adquirida a lo largo del tiempo y el espacio (RIVERA-NÚÑEZ, 2019). Hablo de lo nuevo histórico: los presentes-pasados-futuros agroecológicos.

\section{REFERENCIAS BIBLIOGRÁFICAS}

ABEL, T. Complex adaptive systems, evolutionism, and ecology within anthropology: interdisciplinary research for understanding cultural and ecological dynamics. Journal of Ecological Anthropology, v. 2, n. 1, p. 6-29, 1998.

AGAR, M. We have met the other and we're all nonlinear: Ethnography as a nonlinear dynamic system. Complexity, v. 10, n. 2, p. 16-24, 2004.

ALBERONI, F. Movement and institution. New York: Columbia University Press, 1984.

ALMADA, E. Urban socio-biodiversity: ethnoecology of cities. Bioremediation, Biodiversity and Bioavailability, v. 5, p. 1-8, 2011.

ALTIERI, M. Agroecology. The scientific basis of alternative agriculture. Boulder: Westview Press, 1987.

ALTIERI, M. A. Ethnoscience and biodiversity: Key elements in the design of sustainable pest management systems for small farmers in developing countries. Agriculture, Ecosystems \& Environment, v. 46. n. 1-4, p. 257-72, 1993.

ALTIERI, M. A.; NICHOLLS, C. I. Scaling up agroecological approaches for food sovereignty in Latin America. Development, v. 51, n. 4, p. 472-80, 2008.

ALTIERI, M. A.; NICHOLLS, C. I. Agroecology: a brief account of its origins and currents of thought in Latin America. Agroecology and Sustainable Food Systems, v. 41, n. 3-4, p. 231-37, 2017.

ALTIERI, M. A.; TOLEDO, V. M. The agroecological revolution in Latin America: rescuing nature, ensuring food sovereignty and empowering peasants. Journal of Peasant Studies, v. 38, n. 3, p. 587-612, 2011.

ARMSTRONG, C. G.; SHOEMAKER, A. C.; MCKECHNIE, I.; EKBLOM, A.; SZABÓ, P.; LANE, P. J.; GIBBONS, K. S. Anthropological contributions to historical ecology: 50 questions, infinite prospects. PloS One, v. 12, n. 2, p. 171-83, 2017.

ARMSTRONG, C. G.; VETETO. J. R. Historical ecology and ethnobiology: applied research for environmental conservation and social justice. Ethnobiology Letters, v. 6, n. 1, p. 5-7, 2015.

ASTIER, M.; ARGUETA, J. Q.; OROZCO-RAMÍREZ, Q.; GONZÁLEZ, M. V.; MORALES, J.; GERRITSEN, P. R.; SÁNCHEZ-SÁNCHEZ, C. Back to the roots: understanding current agroecological 
movement, science, and practice in Mexico. Agroecology and Sustainable Food Systems, v. 41, n. 3-4, p. 32948, 2017.

ATKINSON, P.; HAMMERSLEY, M. Ethnography and participant observation. En: DENZIN, N. K.; LINCOLN, Y. S. (Eds). Handbook of qualitative research. Thousand Oaks, California: Sage, 1994. p. 248261.

ATRAN, S. Folk biology and the anthropology of science: Cognitive universals and cultural particulars. Behavioral and brain sciences, v. 21, n. 4, p. 547-569, 1998.

BAILEY, G. Time perspectives, palimpsests and the archaeology of time. Journal of Anthropological Archaeology, v. 26, n. 2, p. 198-223, 2007.

BALÉE, W. Advances in historical ecology. New York: Columbia Univ. Press, 1998.

BALÉE, W. The research program of historical ecology. Annual Review of Anthropology, v. 35, p. 75-98, 2006.

BALÉE, W. Contingent diversity on anthropic landscapes. Diversity, v. 2, n. 2, p. 163-81, 2010.

BALEE, W. Cultural forests of the Amazon: a historical ecology of people and their landscapes. Tuscaloosa: University of Alabama Press, 2013.

BALICK, M. J.; COX, P. A. Plants, people, and culture: the science of ethnobotany. Scientific American Library, 1996.

BAPTISTA DA COSTA, M. B.; SOUZA, M.; JÚNIOR, V. M.; COMIN, J. J.; LOVATO, P. E. Agroecology development in Brazil between 1970 and 2015. Agroecology and Sustainable Food Systems, v. 41, n. 3-4, p. 276-295, 2017.

BARRERA-BASSOLS, N.; TOLEDO, V. M. Ethnoecology of the Yucatec Maya: Symbolism, knowledge and management of natural resources. Journal of Latin American Geography, p. 9-41, 2005.

BARTHEL, S.; CRUMLEY, C.; SVEDIN, U. Bio-cultural refugia safeguarding diversity of practices for food security and biodiversity. Global Environmental Change, v. 23, n.5, p. 1142-52, 2013.

BATESON, G. Steps to an ecology of mind. London: Fontana, 1973.

BATESON, G. A sacred unity: further steps to an ecology of mind. San Francisco: Harper, 1991.

BELLO BALTAZAR, E.; ESTRADA LUGO, E. I. J. Introducción Cultivar el territorio maya. En: BELLO BALTAZAR, E; ESTRADA LUGO, E. I. J. (Eds). Cultivar el territorio maya. Conocimiento y organización social en el uso de la selva. México: El Colegio de la Frontera Sur, 2011. p. 15-43.

BENÍTEZ, M. Ecological evolutionary developmental biology in dialogue with agroecology: The milpa as model system. INTERdisciplina, v. 6, n. 14, p. 69-87, 2018.

BERKES, F. Sacred ecology: traditional ecological knowledge and resource management. London: London Science and the St Elias, 1999.

BERNARD, H. R. Social research methods: qualitative and quantitative approaches. Thousand Oaks, California: Sage, 2011.

BERNSTEIN, H. Food sovereignty via the 'peasant way': A sceptical view. Journal of Peasant Studies, v. 41, n. 6, p. 1031-1063, 2014.

BERTAUX, D. Los relatos de vida en el análisis social. En: ACEVES, J. (Ed.). Historia oral. Ciudad de México: Antologías Universitarias, Instituto Mora, Universidad Autónoma Metropolitana, 1989. p. 56-81.

BLANTON, R. E.; FARGHER. L. F. Reconsidering Darwinian archaeology: with suggestions for a revised agenda for cooperation research. En: CARBALLO, D. M. (Ed.). Cooperation and collective action: archaeological perspectives. Carballo. Boulder: University Press of Colorado, 2012. p. 93-127.

BOEGE, E. El patrimonio biocultural de los pueblos indígenas de México. México: Instituto Nacional de Antropología e Historia, 2008.

BOIVIN, N. L.; ZEDER, M. A.; FULLER, D. Q.; CROWTHER, A.; LARSON, G.; ERLANDSON, J. M.; PETRAGLIA, M. D. Ecological consequences of human niche construction: examining long-term anthropogenic shaping of global species distributions. Proceedings of the National Academy of Sciences, v. 113, n. 23, p. 6388-6396, 2016.

BOTKIN, D. B. Discordant harmonies: a new ecology for the twenty-first century. New York: Oxford University Press, 1990

BÜSCHER, B.; FLETCHER, R. Towards convivial conservation. Conservation and Society, v. 17, n. 3, p. 283-296, 2019.

BRAUDEL, F. On history. Chicago: University of Chicago Press, 1980

BRESCIA, S. Fertile ground: scaling agroecology from the ground up. USA: Food First/ Institute for Food and Development Policy, 2017.

BROSIUS, P.; LOVELACE, G.; MARTIN, G. Ethnoecology: an approach to understanding traditional agricultural knowledge. En: MARTIN, G. G. (Ed.). Traditional agriculture in southeast Asia. Boulder/London: Westview Pres, 1986. p. 187-98.

BRYANT, R. L.; BAILEY, S. Third world political ecology. New York: Routledge, 1997. 
BRYM, Z. T.; REEVE. J. R. Agroecological principles from a bibliographic analysis of the term agroecology. En: LICHTFOUSE, E. (Ed.). Sustainable agriculture reviews. Berlin: Springer International Publishing, 2016. p. 203-231.

CAHUICH-CAMPOS, D. El huerto maya y la alimentación cotidiana de las familias campesinas de X-Mejía, Hopelchén, Campeche. En: MARIACA-MÉNDEZ, R. (Ed.). El huerto familiar del sureste de México. México: El Colegio de la Frontera Sur, 2012. p. 197-229.

CAHUICH-CAMPOS, D.; HUICOCHEA GÓMEZ, L.; MARIACA-MÉNDEZ, R. El huerto familiar, la milpa y el monte Maya en las prácticas rituales y ceremoniales de las familias de X-Mejía, Hopelchén, Campeche. Relaciones. Estudios de historia y sociedad, v. 35, n. 140, p. 157-84, 2014.

CALLICOTT, J. B. Beyond the land ethic: more essays in environmental philosophy. California: Suny Press, 1999.

CAPRA, F.; LUISI, P. L. The systems view of life: a unifying vision. Cambridge: Cambridge University Press, 2014

CHAZDON, R. L.; HARVEY, C. A.; KOMAR, O.; GRIFFITH, D. M.; FERGUSON, B. G.; MARTÍNEZRAMOS, M. E.; PHILPOTT, S. M. Beyond reserves: a research agenda for conserving biodiversity in humanmodified tropical landscapes. Biotropica, v. 41, n. 2, p. 142-153, 2009.

CLAVAL, P. Los fundamentos actuales de la geografía cultural. Documents D'analisi Geografica, v. 34, p. 25-40, 1999

CLEMENT, C. R. 2006. Demand for two classes of traditional agroecological knowledge in modern Amazonia. En: POSEY, D. A. (Ed.). Human impacts on Amazonia: the role of traditional ecological knowledge in conservation and development. NY: Columbia University Press, 2006. p. 33-50.

CLEMENT, C. R.; JUNQUEIRA, A. B. Between a pristine myth and an impoverished future. Biotropica, v. 42 , n. 5, p. 534-536, 2010.

CLEMENT, C. R.; DENEVAN, W. M.; HECKENBERGER, M. J.; JUNQUEIRA, A. B.; NEVES, E. G.; TEIXEIRA, W. G.; WOODS. W. I. The domestication of Amazonia before European conquest. Proceedings of the Royal Society B: Biological Sciences, v. 282, n. 1812, p. 1-9, 2015.

COLLINS, R. Cuatro tradiciones sociológicas. México: UAM, 1996.

CONNELL, J. H. Diversity in tropical rain forests and coral reefs. Science, v. 199, n. 4335, p. 1302-1310, 1978.

CONTRERAS-CORTÉS, U.; MARIACA-MÉNDEZ, R. Manejo de los recursos naturales entre los mayas lacandones de Nahá. México: El Colegio de la Frontera Sur, 2016.

COOK, S. The forest of the Lacandon Maya. Boston, MA: Springer, 2016.

CRESWELL, J. W. Qualitative inquiry and research design: choosing among five traditions. Thousand Oaks, CA: Sage, 1998.

CROSBY, A. Ecological imperialism: the biological expansion of Europe, 900-1900. Cambridge: Cambridge University Press, 2004.

CRUMLEY, C. Historical ecology: cultural knowledge and changing landscapes. Santa Fe: School of American Research Press, 1994.

CRUMLEY, C. L. Historical ecology. En: CRUMLEY, C. L.; MARQUARDT, W. H. (Eds.). Regional dynamics: Burgundian landscapes in historical perspective. New York: Academic Press, 1987. p. 237-264.

CRUMLEY, C. L.; MARQUARDT, W. H. Landscape: a unifying concept in regional analysis. En: KATHLEEN, M. S.; ALLEN, S.; GREEN, W.; ZUBROW, B. W. (Ed.). Interpreting space: GIS and archaeology. London: Taylor \& Francis, 1990. p. 73-79.

DA COSTA, M. B.; SOUZA, B. M.; JÚNIOR, V. M.; COMIN, J. J.; LOVATO. P. E. Agroecology development in Brazil between 1970 and 2015. Agroecology and Sustainable Food Systems, v. 41, n. 3-4, p. 276-95, 2017.

DE SCHUTTER, O. Agroecology and the right to food. Report presented at the 16th session of the United Nations Human Rights Council, New York, 2011.

DE VOS, J. Una tierra para sembrar sueños. Historia reciente de la selva Lacandona 1950-2000. México: Fondo de Cultura Económica, 2002.

DE VOS, J. La memoria interrogada. Desacatos, v. 15-16, p. 222-236, 2004.

DENEVAN, W. M. The pristine myth: the landscape of the Americas in 1492. Annals of the Association of American Geographers, v. 82, n. 3, p. 369-385, 1992.

DESCOLA, P. In the society of nature: a native ecology in Amazonia. Cambridge: Cambridge University Press, 1996.

DESMARAIS, A. La Vía Campesina: globalization and the power of peasants. Halifax: Fernwood Publishing, 2007.

DODD, J. R.; STANTON. R. J. Paleoecology: concepts and applications. New York: John Wiley \& Sons, 1990.

DOGAN, M.; PAHRE, R. Las nuevas ciencias sociales: la marginalidad creadora. México: Grijalbo, 1993. 
DOVE, M. R. The agronomy of memory and the memory of agronomy: ritual conservation of archaic cultigens in contemporary farming systems. En: NAZAREA, V. (Ed.). Ethnoecology: situated knowledge/located lives. Tucson: The University of Arizona Press, 1999. p. 45-70.

DUNNING, N.; LUZZADDER-BEACH, P., S.; BEACH, T.; JONES, J. G.; SCARBOROUGH, V.; CULBERT. T. P. Arising from the bajos: the evolution of a neotropical landscape and the rise of Maya civilization. Annals of the Association of American Geographers, v. 92, n. 2, p. 267-83, 2002.

ELLIS, E. C. Ecology in an anthropogenic biosphere. Ecological Monographs, v. 85, n. 3, p. 287-331, 2015.

ERICKSON, C. L. An artificial landscape-scale fishery in the Bolivian Amazon. Nature, v. 408, n. 6809, p. 190-193, 2000.

ERICKSON, C. L.; BALÉE, W. The historical ecology of a complex landscape in Bolivia. En: BALÉE, W.; ERICKSON, C. (Eds). Time and complexity in historical ecology: studies in the Neotropical lowlands. New York: Columbia University Press, 2006. p. 187-233.

ESCOBAR, A. Whose knowledge, whose nature? Biodiversity, conservation, and the political ecology of social movements. Journal of Political Ecology, v. 5, n.1, p. 53-82, 1998.

EVANS, J. G.; O'CONNOR, T. P. Environmental archaeology: principles and methods. Sutton Pub Limited, 1999.

FAUST, B. B. El desarrollo rural en México y la serpiente emplumada: tecnología y cosmología maya en la selva tropical de Campeche. México: FCE/Cinvestav, 2010.

FAUST, B. B.; FOLAN, W. J. Pasos largos al futuro: la resiliencia socio-ecológica de los Mayas de Campeche en relación a los cambios climáticos. Campeche: Universidad Autónoma de Campeche, 2016.

FEBVRE, L. P. V. Combats pour l'histoire. Paris: Colin, 1953.

FEDICK, S. L.; MORRISON, B. A.; ANDERSEN, B. J.; BOUCHER, S.; ACOSTA, J. C.; MATHEWS, J. P. Wetland manipulation in the Yalahau region of the northern Maya lowlands. Journal of Field Archaeology, v. 27, n. 2, p. 131-152, 2000 .

FERGUSON, B. G.; MORALES, H. L. Latin American agroecologists build a powerful scientific and social movement. Journal of Sustainable Agriculture, v. 34, p. 339-341, 2010.

FERNÁNDEZ-LLAMAZARES, Á.; CABEZA, M. Rediscovering the potential of indigenous storytelling for conservation practice. Conservation Letters, v. 11, n. 3, p. e12398, 2018.

FILL, A.; PENZ, H. The Routledge handbook of ecolinguistics. Londres: Routledge, 2018.

FORD, A. Adaptive management and the community of El Pilar: A philosophy of resilience for the Maya forest. En: AGNEW, N.; BRIDGLAND, J. (Ed.). Out of the past, for the future: integrating archaeology and conservation, Washington, DC: The Getty Institute, 2006. p. 105-112.

FORD, A. Dominant plants of the Maya forest and gardens of El Pilar: implications for paleoenvironmental reconstructions. Journal of Ethnobiology, v. 28, n. 2, p. 179-199, 2008.

FORD, A. Valuating the forest as a garden. USA: Exploring Solutions Past: The Maya Forest Alliance, 2018

FORD, A.; NIGH. R. B. Origins of the Maya forest garden: Maya resource management. Journal of Ethnobiology, v. 29, n. 2, p. 213-236, 2009.

FORD, A.; NIGH, R. B. The Maya forest garden: eight millennia of sustainable cultivation of the tropical woodlands. London: Routledge, 2015.

FRANCIS, C.; LIEBLEIN, G.; GLIESSMAN, S.; BRELAND, T. A.; CREAMER, N.; HARWOOD, R.; WIEDENHOEFT, M. Agroecology: the ecology of food systems. Journal of Sustainable Agriculture, v. 22, n. 3, p. 99-118, 2003.

FUENTES, A. Integrative anthropology and the human niche: toward a contemporary approach to human evolution. American Anthropologist, v. 117, n. 2, p. 302-315, 2015.

FUNES, F.; GARCÍA, L.; BOURQUE, M.; PÉREZ, N.; ROSSET, P. Sustainable agriculture and resistance: transforming food production in Cuba. Appropriate Technology, v. 29, n. 2, p. 435-460, 2002.

GARCÍA QUINTANILLA, A. G. El dilema de Ah Kimsah K'ax,'el que mata al monte': significados del monte entre los mayas milperos de Yucatán. Mesoamérica, v. 21, n. 39, p. 255-286, 2000.

GARCÍA-FRAPOLLI, E.; AYALA-OROZCO, B.; BONILLA-MOHENO, M.; ESPADAS-MANRIQUE, C.; RAMOS-FERNÁNDEZ, G. Biodiversity conservation, traditional agriculture and ecotourism: Land cover/land use change projections for a natural protected area in the northeastern Yucatan Peninsula, Mexico. Landscape and Urban Planning, v. 83, n. 2-3, p. 137-153, 2007.

GIRALDO, O. F. Utopías en la era de la supervivencia: una interpretación del buen vivir. Chapingo: Editorial Itaca, 2014.

GIRALDO, O. F. Political ecology of agriculture: agroecology and post-development. New York: Springer, 2019.

GIRALDO, O. F.; ROSSET. P. M. Agroecology as a territory in dispute: between institutionality and social movements. The Journal of Peasant Studies, v. 45, n. 3, p. 545-564, 2017.

GLASER, B.; WOODS, W. Amazonian dark earths: explorations in space and time. Berlin: Springer, 2004. 
GLIESSMAN, S. A global vision for food system transformation. Agroecology and Sustainable Food Systems, v. 39, n. 7, p. 725-726, 2015.

GLIESSMAN, S. A brief history of agroecology in Spain and Latin America. Agroecology and Sustainable Food Systems, V. 41, n. 3-4, p. 229-30, 2017.

GLIESSMAN, S. Ecological basis of traditional management of wetlands in tropical Mexico: learning from agroecosystems. En: OLDFIELD, M. L.; ALCORN, J. B. (Eds.). Biodiversity: culture, conservatism, and ecodevelopment. Boulder, Colorado: Westview Press, 1991. p. 211-229.

GLIESSMAN, S. Agroecology and food system change. Journal of Sustainable Agriculture, v. 35, p. 345 349, 2011.

GOFFMAN, E. Where the action is: three essays. London: Penguin Press, 1969.

GOMEZ-POMPA, A.; MORALES, H. L.; AVILLA, E. J.; AVILLA, J. J. Experiences in traditional hydraulic agriculture. En: FLANNERY, K. V. (Ed.). Maya subsistence. New York: Academic Press, 1982. p. 327-42.

GÓMEZ-POMPA, A. On maya silviculture. Mexican Studies/Estudios Mexicanos, v. 3, n. 1, p. 1-17, 1987.

GÓMEZ-POMPA, A. Research challenges for the lowland Maya Area. An introduction. En: GÓMEZPOMPA, A.; ALLEN, M. F.; FEDICK, S. L.; JIMÉNEZ-OSORNIO, J. J. (Eds.). The lowland Maya area. New York: The Haworth Press, 2003. p. 3-12.

GÓMEZ-POMPA, A.; KRAUSS. A. Taming the wilderness myth. Biosciense, v. 42, p. 271-279, 1992.

GONZÁLEZ DE MOLINA, M.; GUZMÁN CASADO, G. Sobre los orígenes andaluces de la agroecología en España y su contribución a la formación del pensamiento agroecológico. Agroecología, v. 11, n. 2, p. 105116, 2016.

GONZÁlez de MOlinA, M.; PETERSEN, P. F.; GARRIDO PEÑA, F.; CAPORAL, F. R. Political agroecology: advancing the transition to sustainable food systems. Boca Ratón: CRC Press, 2019.

GONZÁLEZ-JÁCOME, A. Conversión social y cultural de los agroecosistemas tradicionales a los alternativos en México. Los nuevos caminos de la agricultura: procesos de conversión y perspectivas. México: Universidad Iberoamericana/Plaza Valdés, 2007.

GONZÁLEZ-JÁCOME, A. Historias varias: un viaje en el tiempo con los agricultores mexicanos. México: Universidad Iberoamericana, 2011.

GREENBERG, L. Women in the garden and kitchen: the role of cuisine in the conservation of traditional house lot crops among the Yucatec Mayan immigrants. En: HOWARD, P. L. (Ed.). Women and plants. London: Zed Books, 2003. p. 51-65.

GREENBERG, L. S. Garden hunting among the Yucatec Maya: a coevolutionary history of wildlife and culture. Etnoecológica, v. 1, n. 1, p. 23-33, 1992.

GROESBECK, A. S.; ROWELL, K.; LEPOFSKY, D.; SALOMON, A. K. Ancient clam gardens increased shellfish production: adaptive strategies from the past can inform food security today. PloS One, v. 9, n. 3, p. e91235, 2014.

GUDYNAS, E.; ACOSTA, A. El buen vivir más allá del desarrollo. Revista Qué Hacer, v. 181, p. 70-81, 2011.

GUTHMAN, J. Raising organic: An agro-ecological assessment of grower practices in California. Agriculture and Human Values, v. 17, n. 3, p. 257-266, 2000.

GUZMÁN, E.; ALONSO, A. M. Para una teoría etnoecológica centroperiferia desde la agroecologia. Papel presentado en el I Congreso de la Sociedad Española de Agricultura Ecológica, Valencia, España, 1994.

HARLAN, J. R. Agricultural origins: centers and noncenters. Science, v. 174, n. 4008, p. 468-474, 1971.

HARVEY, C. A.; KOMAR, O.; CHAZDON, R.; FERGUSON, B. G.; FINEGAN, B.; GRIFFITH, D. M.; VAN BREUGEL, M. Integrating agricultural landscapes with biodiversity conservation in the Mesoamerican hotspot. Conservation Biology, v. 22, n. 1, p. 8-15, 2008.

HATHAWAY, M.; BOFF, L. The Tao of liberation: exploring the ecology of transformation. New York: Orbis Books, 2009.

HERNÁNDEZ XOLOCOTZI, E. Agroecosistemas de México. México: Colegio de

Postgraduados/Universidad Autónoma Chapingo, 1977.

HERRERA, F. F.; DOMENÉ-PAINENAO, O.; CRUCES, J. M. The history of agroecology in Venezuela: A complex and multifocal process. Agroecology and Sustainable Food Systems, v. 41, n. 3-4, p. 401-415, 2017.

HOLLING, C. S. Resilience and stability of ecological systems. Annual Review of Ecology and Systematics, v. 4, n. 1, p. 1-23, 1973.

HOLT-GIMÉNEZ, E. Campesino a campesino: voices from Latin America's farmer to farmer movement for sustainable agriculture. Oakland, CA: Food First Books, 2006.

INGOLD, T. The perception of the environment: essays on livelihood, dwelling and skill. London: Routledge, 2002.

JIMÉNEZ-OSORNIO, J. J.; RUENES, M. D.; MONTAÑEZ, P. Agrodiversidad de los solares de la Península de Yucatán. Red de gestión de recursos naturales, v. 14, p. 30-40, 1999. 
JIMÉNEZ-OSORNIO, J.; ZARCO, M.; LENDECHY, A.; BECERRIL, J. Los solares: una oportunidad para contribuir a la seguridad alimentaria, mitigación y cambio climático en Yucatán. En: CANTO, R.; ZARCO, M. (Ed.). Extensión y responsabilidad social. Los proyectos sociales en comunidades de aprendizaje implementados en la Universidad Autónoma de Yucatán. México: Universidad Autónoma de Yucatán, 2015. p. 237-266.

KENDAL, J. R. Cultural niche construction and human learning environments: Investigating sociocultural perspectives. Biological Theory, v. 6, n. 3, p. 241-250, 2011.

KHADSE, A.; ROSSET, P. M.; MORALES, H. L; FERGUSON, B. G. Taking agroecology to scale: the zero budget natural farming peasant movement in Karnataka, India. The Journal of Peasant Studies, v. 45, n. 1, p. 192-219, 2017

LALAND, K.; ULLER, T.; FELDMAN, M; STERELNY, K.; MÜLLER, G. B.; MOCZEK, A.; FUTUYMA, D. J. Does evolutionary theory need a rethink? Nature News, v. 514, n. 7521, p. 161, 2014.

LANSING, J. S. Perfect order: recognizing complexity in Bali. NJ: Princeton University Press, 2012.

LANSING, J. S.; FOX. K. M. Niche construction on Bali: The gods of the countryside. Philosophical Transactions of the Royal Society of London B: Biological Sciences, v. 366, n. 1566, p. 927-934, 2011.

LEFF, E. Aventuras de la epistemología ambiental: de la articulación de ciencias a al diálogo de saberes, Siglo XXI, 2007.

LE GOFF, J. El orden de la memoria: el tiempo como imaginario. Barcelona: Paidos, 1991.

LEOPOLD, A. The conservation ethic. Journal of Forestry, v. 31, n. 6, p. 634-643, 1933.

LEOPOLD, E. B.; BOYD. R. An ecological history of old prairie areas in southwestern Washington. En: BOYT, R. (Ed.). Indians, fire and the land in the Pacific Northwest. Corvallis: Oregon State University Press, 1999. p. 139-163.

LÉVI-STRAUSS, C. El pensamiento salvaje. México: Fondo de Cultura Económica, 1964.

LEVINS, R.; LEWONTIN, R. C. The dialectical biologist. Cambridge, MA: Harvard University Press, 1985.

LEWIS, O. Five families: Mexican case studies in the culture of poverty. With a foreword by Oliver La Farge. New York: Basic Books, 1959.

LINDBORG, R.; ERIKSSON. O. Historical landscape connectivity affects present plant species diversity. Ecology, v. 85, n. 7, p. 1840-1845, 2004.

LONG, N.; ROBERTS, B. Changing rural scenarios and research agendas in Latin America in the new century. En: BUTTEL, F. H.; MCMICHAEL, P. (Eds.). Research in rural sociology and development: new directions in the sociology of global development. Amsterdam: Elsevier, 2005. p. 57-90.

MACHÍN SOSA, A.; ROQUE, A. M.; ÁVILA, D. R.; ROSSET, P. M. Agroecological revolution: the farmer-to-farmer movement of the ANAP in Cuba. Havana: ANAP and La Via Campesina, 2013.

MARES, T. M.; PEÑA, D. G. Urban agriculture in the making of insurgent spaces. En: HOU, J. (Ed.). Insurgent public space: guerrilla urbanism and the remaking of contemporary cities. Abingdon: Routledge, 2010. p. 241-254.

MARIACA MÉNDEZ, R.; GONZÁLEZ JÁCOME, A.; MARTÍNEZ, L. El huerto familiar en México: avances y propuestas. En: LÓPEZ OLGUÍN, J. F.; ARAGÓN GARCÍA, A.; TAPIA ROJAS, A. M. (Eds.). Avances en agroecología y ambiente. Puebla, México: Benemérita Universidad Autónoma de Puebla, 2007. p. 119-138

MARIACA MÉNDEZ, R. La complejidad del huerto familiar maya del sureste de México. En: MARIACA,

R. (Ed.). El huerto familiar del sureste de México. México: El Colegio de la Frontera Sur, 2012. p. 7-97.

MARION SINGER, M. O. Bajo la sombra de la gran ceiba: la cosmovisión de los lacandones. Desacatos, v. 5, p. 45-56, 2000.

MARRIS, E. Black is the new green. Nature, v. 442, p. 624-626, 2006.

MARTÍNEZ-ALIER, J. The environmentalism of the poor: study of ecological conflicts and valuation. Cheltenham: Edward Elgar, 2002

MARTÍNEZ-TORRES, M. E.; ROSSET, P. M. Diálogo de saberes in La Vía Campesina: food sovereignty and agroecology. Journal of Peasant Studies, v. 41, n. 6, p. 979-997, 2014.

MCCUNE, N. Family, territory, nation: post-neoliberal agroecological scaling in Nicaragua. Food Chain, v. 6, n. 2, p. 92-106, 2016.

MCCUNE, N.; REARDON, J.; ROSSET. P. M. Agroecological formation in rural social movements.

Radical Teacher, v. 98, p. 31-37, 2014

MCCUNE, N.; SÁNCHEZ, M. Teaching the territory: agroecological pedagogy and popular movements.

Agriculture and Human Values, v. 35, p. 1-16, 2018.

MCNEILL, J. R. Observations on the nature and culture of environmental history. History and Theory, v. 42, p. 5-43, 2003.

MELLUCI, A. The process of collective identity. En: JOHNSTON, H.; KLANDERMANS, B. (Eds.). Social movements and culture. Minneapolis: University of Minnesota Press, 1994. p. 41-63. 
MENDEZ, V. E.; BACON, C. M.; COHEN, R. Agroecology as a transdisciplinary, participatory, and actionoriented approach. Agroecology and Sustainable Food Systems, v. 37, 1, p. 3-18, 2013.

MERÇON, J.; VETTER, S.; TENGÖ, M.; COCKS, M.; BALVANERA, P.; ROSELL, J. A.; AYALA-

OROZCO, B. From local landscapes to international policy: contributions of the biocultural paradigm to global sustainability. Global Sustainability, v. 2, n. 7, p. 1-11, 2019.

MEYER, W. J.; CRUMLEY, C. L. Historical ecology: using what works to cross the divide. En: MORRE, T.; ARMADA, X. L. (Ed.). Atlantic Europe in the first millennium BC: crossing the divide. New York, USA: Oxford University Press, 2011. p. 109-134.

MIER Y TERÁN, M.; GIRALDO, O. F.; ALDASORO, M.; MORALES, H. L.; FERGUSON, B. G.; ROSSET, P. M.; CAMPOS, C. Bringing agroecology to scale: key drivers and emblematic cases. Agroecology and Sustainable Food Systems, v. 42, n. 6, p. 637-665, 2018.

MINTZ, S. W.; DU BOIS, C. M. The anthropology of food and eating. Annual Review of Anthropology, v. 31, n. 1, p. 99-119, 2002.

MISTRY, J.; BERARDI, A.; ANDRADE, V.; KRAHÔ, T.; KRAHÔ, P.; LEONARDOS, O. Indigenous fire management in the cerrado of Brazil: the case of the Krahô of Tocantíns. Human Ecology, v. 33, n. 3, p. 365386, 2005.

MORALES, H. L.; FERGUSON, B. G.; GARCÍA-BARRIOS, L. E. Agricultura: la cenicienta de la conservación en Mesoamérica. En: HARVEY, C.; SÁENZ, C. (Eds.). Evaluación y conservación de biodiversidad en paisajes fragmentados de Mesoamérica. Heredia: INBio, 2007. p. 47-73.

MORAN, E. F. People and nature: an introduction to human ecological relations. NJ: John Wiley and Sons, 2016.

MOYO, S. Three decades of agrarian reform in Zimbabwe. Journal of Peasant Studies, v. 38, n. 3, p. 493 531,2011

NABHAN, G. P. Enduring seeds: native American agriculture and wild plant conservation. Tucson: University of Arizona Press, 2016.

NASSAUER, J. I.; OPDAM, P. Design in science: extending the landscape ecology paradigm. Landscape Ecology, v. 23, n. 6, p. 633-644, 2008.

NATIONS, J. D.; NIGH, R. B. The evolutionary potential of Lacandon Maya sustained-yield tropical forest agriculture. Journal of Anthropological Research, v. 36, n. 1, p. 1-30, 1980.

NAZAREA, V. D. A view from a point: ethnoecology as situated knowledge. En: HAENN, N.; WILK, R.; HARNISH, A. (Eds.). The environment in anthropology: a reader in Ecology. New York: New York University Press, 2016. p. 41-48.

NIGH, R. B. Trees, fire and farmers: making woods and soil in the Maya forest. Journal of Ethnobiology, v. 28 , n. 2, p. 231-43, 2008 .

NIGH, R. B.; GONZÁLEZ-CABAÑAS, A. A. Reflexive consumer markets as opportunities for new peasant farmers in Mexico and France: constructing food sovereignty through alternative food networks. Agroecology and Sustainable Food Systems, v. 39, n. 3, p. 317-341, 2015.

NIGH, R. B.; DIEMONT, S. A. The Maya milpa: fire and the legacy of living soil. Frontiers in Ecology and the Environment, v. 11, n.1, p. 45-54, 2013.

NIGH, R. B.; FORD, A. El Jardín forestal maya. Ocho milenios de cultivo sostenible de los bosques tropicales. San Cristóbal de las Casas: Fray Bartolomé de las Casas/CIESAS/Exploring Solutions Past the Maya Forest Alliance, 2019.

ODLING-SMEE, F. J.; ODLING-SMEE, H.; LALAND, K. N.; FELDMAN, M. W.; FELDMAN, F. Niche construction: the neglected process in evolution. NJ: Princeton university press, 2003.

ODLING-SMEE, F. J.; LALAND, K. N.; FELDMAN. M. W. Niche construction. The American Naturalist, v. 147, n. 4, p. 641-648, 1996.

ODUM, E. P. Properties of agroecosystems. En: LOWRANCE, R.; STINNER, B. R. (Eds.). Agricultural ecosystems: unifying concepts. New Jersey: Wiley, 1984. p. 5-11.

OSTROM, E. Governing the commons: the evolution of institutions for collective action. Cambridge: Cambridge University Press, 1990.

PALERM, A.; WOLF, E. Agricultura y civilización en Mesoamérica. México: SEP/ Setentas-DIANA, 1972.

PAOLI, A. Educación, autonomía y Lekil Kuxlejal: aproximaciones sociolingüísticas a los Testales. México: Universidad Autónoma Metropolitana, 2003.

PARMENTIER, S. Scaling-up agroecological approaches: what, why and how? Belgium: Oxfam Solidarity, 2014.

PARSONS, T. The social system. New York, NY: Free Press Paperback, 1964.

PASTOR-ALFONSO, M. J.; GÓMEZ LÓPEZ, D.; ESPESO-MOLINERO, P. Turismo comunitario y sus consecuencias entre los lacandones de Chiapas: organismos y sistemas de apoyo. Pasos. Revista de Turismo y Patrimonio Cultural, v. 10, p. 23-43, 2012. 
PELLEGRINI, P. Knowledge, identity and ideology in stances on GMOs: the case of the movimento Sem Terra in Brazil. Science Studies, v. 22, n. 1, p. 44-63, 2009.

PERFECTO, I.; VANDERMEER, J. The agroecological matrix as alternative to the land-sparing/agriculture intensification model. Proceedings of the National Academy of Sciences, v. 107, n. 13, p. 5786-5791, 2010.

PERFECTO, I.; VANDERMEER, J.; WRIGHT, A. Nature's matrix: linking agriculture, conservation and food sovereignty. London: Routledge, 2019.

PETERS, C. M.; BALICK, M. J.; KAHN, F.; ANDERSON, A. B. Oligarchic forests of economic plants in Amazonia: utilization and conservation of an important tropical resource. Conservation Biology, v. 3, n. 4, p. 341-349, 1989.

PORTER-BOLLAND, L.; SÁNCHEZ GONZÁLEZ, M. C.; ELLIS, E. A. La conformación del paisaje y el aprovechamiento de los recursos naturales por las comunidades mayas de La Montaña, Hopelchén, Campeche. Investigaciones geográficas, v. 66, p. 65-80, 2008.

PRATT, M. L. Arts of the contact zone. Profession, v. 91, p. 33-40, 1991.

PUC-ALCOCER, M.; ARCE-IBARRA, A. M.; CORTINA-VILLAR, S.; ESTRADA-LUGO, E. I. Rainforest conservation in Mexico's lowland Maya area: integrating local meanings of conservation and land-use dynamics. Forest Ecology and Management, v. 448, p. 300-311, 2019.

REDFIELD, R.; VILLA ROJAS, Y. A. Chan Kom a Maya Village. Chicago: The University of Chicago Press, 1967.

RHEMTULLA, J. M.; MLADENOFF, D. J. Why history matters in landscape ecology. Landscape Ecology, v. 22, n. 1, p. 1-3, 2007.

RIVERA-NÚNEZZ, T. ¿Conservacionismo biológico o agencia humana en el manejo ambiental? El caso del Área de Protección de Flora y Fauna Otoch Ma’ax Yetel Kooh. MSc diss., CINVESTAV-IPN, 2014.

RIVERA-NÚÑEZ, T. Writing over that which is already written: reconceiving biodiversity conservation in a second world according to the concept of "palimpsest". En: WYBORN, C.; KALAS, N.; RUST, N. (Eds.). Seeds of change: provocations for a new research agenda. Vienna: Luc Hoffmann Institute/WWF/Future Earth/ ETH Zürich/University of Cambridge/University College London, 2019. p. 143-146.

RIVERA-NÚÑEZ, T.; FARGHER, L. F.; NIGH, R. B. Toward an historical agroecology: an academic approach in which time and space matter. Agroecology and Sustainable Food Systems, v. 44, p. 1-37, 2020.

ROBBINS, P. Political ecology: a critical introduction. NJ: John Wiley \& Sons, 2011.

ROBBINS, P.; MOORE, S. A. Ecological anxiety disorder: diagnosing the politics of the anthropocene. Cultural Geographies, v. 20, n. 1, p. 3-19, 2013.

ROSADO-MAY, F. J. The intercultural origin of agroecology: contributions from Mexico. En: MÉNDEZ, V. E.; BACON, C. M.; COHEN, R.; GLIESSMAN, S. R. (Eds.) Agroecology: a transdisciplinary, participatory and action-oriented approach. London: Taylor and Francis, 2015. p. 123-138.

ROSSET, P. M.; MARTÍNEZ-TORRES. M. A. Food sovereignty and agroecology in the convergence of rural social movements. En: MARSDEN, T. (Ed.). Alternative agrifood movements: patterns of convergence and divergence. London: Emerald Publishing, 2014. p. 137-157.

ROSSET, P. M. Social organization and process in bringing agroecology to scale. Agroecology for food security and nutrition. Proceedings of the FAO International Symposium, Roma: FAO, 2015.

ROSSET, P. M.; ALTIERI, M. A Agroecology: science and politics. Halifax: Fernwood, 2017.

ROSSET, P. M.; MARTÍNEZ-TORRES, M. E. Rural social movements and agroecology: context, theory, and process. Ecology and Society, v. 17, p. 3-17, 2012.

ROSSET, P. M.; MARTÍNEZ-TORRES, M. E. Agroecología, territorio, recampesinización y movimientos sociales. Estudios Sociales. Revista de Alimentación Contemporánea y Desarrollo Regional, v. 25, n. 47, p. 273-299, 2016.

SANTOS, M. Metamorfoses do espaço habitado: fundamentos teórico e metodológico da geografia. São Paulo: Hucitec, 1988.

SANTOS, M. La naturaleza del espacio: técnica y tiempo. Razón y emoción. Barcelona: Ariel, 2000.

SANTOS-FITA, D.; NARANJO-PIÑERA, E. J.; BELLO-BALTAZAR, E.; ESTRADA-LUGO, E. I. J.; MARIACA- MÉNDEZ, R.; MACARIO-MENDOZA, P. La milpa comedero-trampa como una estrategia de cacería tradicional maya. Estudios de Cultura Maya, v. 42, n. 42, p. 87-118, 2013.

SAUER, C. The agency of man on the earth. Chicago: University of Chicago Press, 1956.

SAUER, C. The morphology of landscape. Berkeley: University of California Press, 1925.

SCOONES, I.; MARONGWE, N.; MAVEDZENGE, B.; MAHENEHENE, J.; MURIMBARIMBA, F.; SUKUME, C. Zimbabwe's land reform: myths and realities. Suffolk, UK: Boydell \& Brewer, 2010.

SCOTT, J. C. Domination and the arts of resistance: hidden transcripts. New Haven, Connecticut: Yale University Press, 1990.

SEVILLA-GUZMÁN, E. Desde el pensamiento social agrario. Servicio de Publicaciones: Universidad de Córdoba, 2006. 
SEVILLA GUZMÁN, E.; ALONSO MIELGO, A. Para una teoría etnoecológica centro-periferia desde la Agroecología. En: CONGRESO DE LA SOCIEDAD ESPAÑOLA DE AGRICULTURA ECOLÓGICA, 1.

Libro de Actas... Toledo, España, 1994. p. 448-460.

SEVILLA-GUZMÁN, E.; WOODGATE. G. Agroecología: fundamentos del pensamiento social agrario y teoría sociológica. Agroecología, v. 8, n. 2, p. 27-34, 2014.

SOLURI, J. History's freaks of nature. Environmental History, v. 10, n. 1, p. 94-95, 2005.

STAKE, R. E. The art of case study research. New Castle upon Tyne: Sage, 1995.

STIBBE, A. Ecolinguistics: language, ecology and the stories we live by. London: Routledge, 2015.

TAPIA, N. Agroecología y agricultura campesina sostenible en los Andes bolivianos: el caso del ayllu Majasaya Mujlli, Departamento de Cochabamba. Bolivia: Plural editores, 2002.

TERÁN, S.; RASMUSSEN, C. H. Xocén, el pueblo en el centro del mundo: Universidad Autónoma de Yucatán, 2005.

TERÁN, S.; RASMUSSEN, C. H. La milpa de los mayas. Mérida, Yucatán: Universidad de Oriente/CEPHCIS-UNAM, 2009.

THOMPSON, J. E. S. Historia y religión de los mayas. México: Siglo XXI, 1975.

THURSTON, T. L.; C. T. FISHER. Seeking a richer harvest. Boston, MA: Springer, 2007.

TOLEDO, V. M. What is ethnoecology? Origins, scope and implications of a rising discipline.

Etnoecológica, v. 1, n. 1, p. 5-21, 1992.

TOLEDO, V. M. La memoria tradicional: La importancia agroecológica de los saberes locales. Leisa

Revista de Agroecología, v. 20, n. 4, p. 16-19, 2005.

TOLEDO, V. M.; BARRERA-BASSOLS, N. Political agroecology in mexico: a path toward sustainability.

Sustainability, v. 9, n. 2, p. 268, 2017.

TOLEDO, V. M.; BARRERA-BASSOLS, N.; GARCÍA-FRAPOLLI, E.; ALARCÓN-CHAIRES, P. Uso

múltiple y biodiversidad entre los mayas yucatecos (México). Interciencia, v. 33, n. 5, p. 345-352, 2008.

TOLEDO, V. M.; ALARCÓN-CHÁIRES, P.; BARÓN, L. Revisualizar lo rural desde una perspectiva multidisciplinaria. Polis, Revista de la Universidad Bolivariana, v. 8, n. 22, p. 328-345, 2009.

TOURAINE, A. Actores sociales y pautas de acción colectiva en América Latina. Santiago: PREALC, 1984

TROLL, C. Ecología del paisaje. Gaceta ecológica, n. 68, p. 71-84, 2003.

TURNER, B. L. II. Agricultura intensiva en las Tierras Bajas Mayas: una lección del pasado. Biótica, v. 2, p. 69-79, 1980.

TRENCH, T. Representaciones y sus impactos: el caso de los lacandones en la Selva Lacandona. Liminar, v. 3, n. 2, p. 48-69, 2005.

VAN DER PLOEG, J. D. The peasantries of the twenty-first century: the commoditisation debate revisited.

The Journal of Peasant Studies, v. 37, n. 1, p. 1-30, 2010.

VAN DER PLOEG, J. D.; YE, J.; PAN, L. Peasants, time and the land: the social organization of farming in

China. Journal of Rural Studies, v. 36, p. 172-181, 2014.

VANDERMEER, J. The ecological basis of alternative agriculture. Annual Review of Ecology and Systematics, v. 26, n. 1, p. 201-224, 1995.

VANDERMEER, J.; PERFECTO, I. The agricultural matrix and a future paradigm for conservation.

Conservation Biology, v. 21, n. 1, p. 274-277, 2007.

VANDERMEER, J., PERFECTO, I. Ecological complexity and agroecology. London: Routledge, 2017.

VAL, V.; ROSSET, P. M.; ZAMORA LOMELÍ, C.; GIRALDO, O. F.; ROCHELEAU, D. Agroecology and

La Via Campesina I. The symbolic and material construction of agroecology through the dispositive of "peasant-

to-peasant" processes. Agroecology and Sustainable Food Systems, v. 43, n. 7-8, p. 872-894, 2019.

VIDAL DE LA BLACHE, P. De l'interprétation géographique des paysages. Neuvième congrès international de géographie, Genève, 1908.

WADDINGTON, C. H. Evolutionary adaptation. Perspectives in Biology and Medicine, v. 2, n. 4, p. 379401, 1959.

WARMAN, A. Estrategias de sobrevivencia de los campesinos mayas. México: Instituto de Investigaciones Sociales, UNAM, 1985.

WEST, P.; BROCKINGTON, D. An anthropological perspective on some unexpected consequences of protected areas. Conservation Biology, v. 20, n. 3, p. 609-616, 2006.

WEZEL, A.; BRIVES, H.; CASAGRANDE, M.; CLÉMENT, C.; DUFOUR, A.; VANDENBROUCKE, P. Agroecology territories: places for sustainable agricultural and food systems and biodiversity conservation. Agroecology and Sustainable Food Systems, v. 40, n. 2, p. 132-144, 2016.

WEZEL, A.; GOETTE, J.; LAGNEAUX, E.; PASSUELlO, G.; REISMAN, E.; RODIER, C.; TURPIN, G. Agroecology in Europe: research, education, collective action networks, and alternative food systems. Sustainability, v. 10, n. 4, p. 1214, 2018.

WEZEL, A.; BELLON, S.; DORÉ, T.; FRANCIS, C.; VALLOD, D.; DAVID, C. Agroecology as a science, a movement and a practice. A review. Agronomy for Sustainable Development, v. 29, n. 4, p. 503-515, 2009. 
WEZEL, A.; SOLDAT, V. A quantitative and qualitative historical analysis of the scientific discipline of agroecology. International Journal of Agricultural Sustainability, v. 7, n. 1, p. 3-18, 2009.

WIBBELMAN, M.; SCHMUTZ, U.; WRIGHT, J.; UDALL, D.; RAYNS, F.; KNEAFSEY, M.; TRENCHARD, L.; BENNETT, J.; LENNARDSSON, M. Mainstreaming agroecology: implications for global food and farming systems. Centre for Agroecology and Food Security, Coventry: Centre for Agroecology and Food Security Discussion Paper, 2013.

WILSHUSEN, P. R.; BRECHIN, S. R.; FORTWANGLER, C. L.; WEST, P. C. Reinventing a square wheel: Critique of a resurgent" protection paradigm" in international biodiversity conservation. Society \& Natural Resources, v. 15, n. 1, p. 17-40, 2002.

WOLF, E. R. Europe and the people without history. Berkeley: University of California Press, 1982.

WYNDHAM, F. S. The sphere of the mind: reviving the noosphere concept for ecological anthropology. Journal of Ecological Anthropology, v. 4, n. 1, p. 87-91, 2000.

YIN, R. K. Case study research. Newbury Park, CA: Sage, 1994.

ZIMMERER, K. S. The reworking of conservation geographies: nonequilibrium landscapes and naturesociety hybrids. Annals of the Association of American Geographers, v. 90, n. 2, p. 356-369, 2000.

ZIMMERER, K. S.; DE HAAN, S.; JONES, A. D.; CREED-KANASHIRO, H.; TELLO, M.; CARRASCO, M.; OLIVENCIA, Y. J. The biodiversity of food and agriculture (Agrobiodiversity) in the anthropocene: research advances and conceptual framework. Anthropocene, v. 25, n. 100192, p. 1-16, 2019. 